"This is the peer reviewed version of the following article: [AIChE Journal, 2015, 61 (12), pp. 4377 - 4386], which has been published in final form at [http://dx.doi.org/10.1002/aic.14906]. This article may be used for non-commercial purposes in accordance with Wiley Terms and Conditions for Self-Archiving." 


\section{A filtration model for prediction of local flux distribution and optimization of submerged hollow fiber membrane module}

\section{Xianhui Li, Jianxin Li, Hong Wang, Xiaoxu Huang and Benqiao He}

State Key Laboratory of Separation Membranes and Membrane Processes, School of Materials Science and Engineering, Tianjin Polytechnic University, Tianjin 300387, PR

China

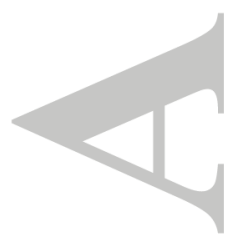

Department of Mathematics, Tianjin Polytechnic University, Tianjin 300387, P. R. China

\section{Yonghong Yao}

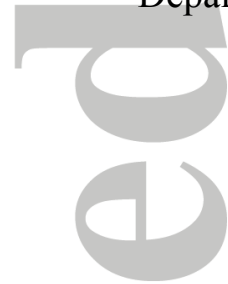

School of Environmental and Chemical Engineering, Tianjin Polytechnic University,

Jie Wang and Hongwei Zhang

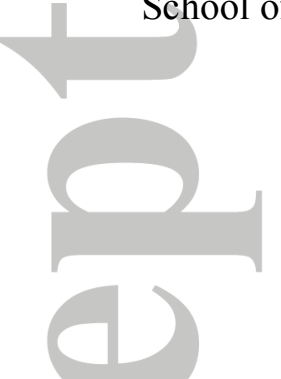

Tianjin 300387, PR China

School of Civil and Environmental Engineering, University of Technology Sydney, PO

Box 123, NSW 2007, Australia

\section{Huu Hao Ngo and Wenshan Guo}

Correspondence concerning this article should be addressed to Jianxin Li at jxli@tjpu.edu.cn

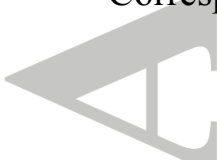

This article has been accepted for publication and undergone full peer review but has not been through the copyediting, typesetting, pagination and proofreading process which may lead to differences between this version and the Version of Record. Please cite this article as doi: $10.1002 /$ aic. 14906

(C) 2015 American Institute of Chemical Engineers (AIChE)

Received: Mar 16, 2015; Revised: Jun 02, 2015; Accepted: Jun 13, 2015 
Revised manuscript AIChE-15-16842R2 for submission to AIChE Journal

A filtration mathematical model was developed on the basis of complete mass balance and momentum balance for the local flux distribution prediction and optimization of submerged hollow fiber membrane module. In this model, the effect of radial permeate flow on internal flow resistance was considered through a slip parameter obtained from the local flux experiments. The effects of fiber length, inside diameter and average operating flux on local flux distribution were investigated using this model. The predicted results were in good agreement with the experimental data obtained from literature. It was also found that the asymmetry distribution of local flux could be intensified with the increase of average operating flux and fiber length, but slowed down with the increase of fiber inside diameter. Furthermore, the simulation coupled with energy consumption analysis could efficiently predict and illustrate the relationship between fiber geometry and water production efficiency.

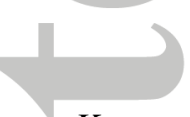

Key words: Filtration mathematical model; Submerged hollow fiber membrane; Local flux distribution; Momentum balance; Mass balance

\section{Introduction}

The submerged membrane filtration has been increasingly used in membrane bioreactor and wastewater treatment processes in recent years. ${ }^{1,2}$ In particular, the submerged hollow fiber membrane systems have gained more popularity than either flat-sheet or tubular membrane modules due to lower cost in fabrication and energy saving in operation., ${ }^{3,4}$ However, it is very difficult to control the hydrodynamics of such systems owning to the 
non-uniform local flux distribution along the hollow fiber membrane. ${ }^{5}$ As a result, hollow fibers may be more prone to fouling and require more frequent washing and cleaning. ${ }^{6}$

Recently, a number of studies on modeling and optimization of the submerged hollow fiber membrane module have been carried out to alleviate membrane fouling and increase filtration efficiency. Chang and Fane $^{7}$ developed a mathematic model for submerged hollow fiber filtration under constant flux operating mode by combining Hagen-Poiseuille equation with the concept of critical flux. In this study, the effects of fiber characteristics (length, radius and membrane resistance) on local flux distribution along the fiber were investigated. Chang et al. ${ }^{8}$ further reported an improved model using the cake filtration theory developed by Petsev et al. ${ }^{9}$. They found that the accumulation of particles on the membrane surface could affect the local flux distribution. Based on the basic method provided by Chang et al. ${ }^{8}$, Ding et al. ${ }^{10}$ predicted the time-dependent filtration performance under different bubbling conditions by introducing a parameter called gas bubbling cleaning efficiency. At the same time, Lee et al. ${ }^{11}$ also proposed a model based on pore-blocking theory to predict transmembrane pressure (TMP) increase during the filtration of starch solution.

In addition, Lee et al. ${ }^{12}$ developed a quantitative method to determine the major fouling during drinking water production under various conditions through combining three different fouling mechanisms such as standard blocking, complete blocking and cake formation. Similarly, by examining pressure drop cross the membrane and cake separately, Kinčl et al. ${ }^{13}$ developed a fundamental mathematical analysis for local flux distribution along the hollow fiber with compressible cake formation. To achieve maximum energy 
efficiency, Yoon et al. ${ }^{14}$ established and discussed a model covering packing density and module configuration as well as the optimum range of fiber diameter and fiber length for one-side and two-side suctions.

Although the development of above models is based upon the Hagen-Poiseuille theory to illustrate the relationship between flux profile and operating and design parameters of hollow fibers, as a basic hydrodynamic equation, the Hagen-Poiseuille equation is commonly applied to describe the flow law of liquids in horizontal and impermeable pipe. Thus, the limitation of the Hagen-Poiseuille equation greatly hinders its practical applications because the effects of transmembrane flow resistance on local permeate flux and pressure drop have not been taken into account. To consider the effect of transmembrane flow on pressure drop and obtain more accurate predictions of filtration behavior, $\mathrm{Yeh}^{15}$ developed a correlation equation derived from the complete momentum balance coupled with the application of exponential model to predict the permeate flux of hollow fiber ultrafiltration membrane. The simulated results showed that the effect of operating pressure on permeate flux is more significant than that of feed concentration.

Especially, Kim et al. ${ }^{16}$ described a perturbation approach of the Navier-Stokes and continuity equations to investigate the effect of membrane length and hydraulic resistance on the steady-state laminar flow of the fluid in the fiber lumen. It indicated that the flow velocity in fiber lumen represents the exponential variation along the axial direction. Although these models provide valuable insight into the filtration behavior under various operating conditions, they only focused on the overall separation performance rather than local filtration behavior. In addition, as the simulated results have been barely proved by 
experimental tests, the applications of these theoretical works are limited. Consequently, it is of great significance to develop an experimental method to measure local flux distribution along the fiber for filtration mathematical model construction.

Herein, to experimentally investigate the local filtration performance of individual fiber, a new experimental method on the basis of iteration method was proposed to measure local fluxes along the submerged hollow fibers in our previous study. ${ }^{17}$ The results showed that the local flux distribution in the double-end filtration mode was more uniform than that in the dead-end filtration mode at the same operating conditions. Additionally, the local flux results coupled with ultrasonic measurements confirmed that the fouling behavior on the membrane surface was consistent with the local flux distribution.

The aim of the present study was to develop a filtration mathematical model to predict local flux distribution so as to optimize submerged hollow fiber membrane on the basis of the complete mass balance and momentum balance. In this model, the effect of radial permeate flow on internal flow resistance of hollow fiber was considered through a slip parameter obtained from the local flux measurements. The effects of average operating flux,

fiber length and inside diameter on local flux distribution were investigated. Meanwhile, to provide a theoretical foundation for the optimization of hollow fiber membrane module, the model was employed to predict the relationship between design and operating parameters of submerged hollow fiber membrane module and its water production efficiency.

\section{Modeling development}

The schematic diagram of deionized water filtration through a submerged hollow fiber 
membrane is shown in Figure 1, where $\mathrm{z}$ and $\mathrm{r}$ are longitudinal and radial coordinates, respectively. The negative pressure is applied to the interior at the open or suction end $(\mathrm{z}=\mathrm{L})$ to generate permeate flux that increases along the fiber from the dead end $(\mathrm{z}=0)$. The basic assumptions underlying the model formulation are listed as follows:

(1) The flow in the fiber lumen is laminar flow in stationary flow.

(2) The fibers are identically aligned against one another as rigid cylinders in a module, and then the simulation of a single fiber can be used to understand the module behavior.

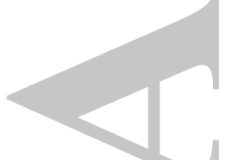

\section{(Insert Figure 1 here)}

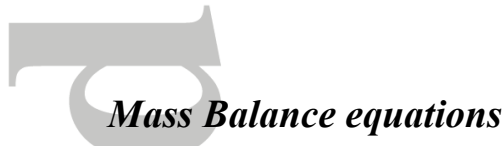

The total length of hollow fiber membrane should be divided into $\mathrm{N}$ small segments in order to consider mass balance in the hollow fiber membrane. At a steady state, mass balance for water over a segment $\Delta \mathrm{z}$ of the fiber is depicted as:

$$
\mathrm{q}(z+\Delta z)=\mathrm{q}(z)+\mathrm{J}(z) \pi D \Delta z
$$

where $q(z)$ is local flow rate inside the fiber, $J(z)$ is local permeate flux and D is outside diameter of fiber. Eq. (1) denoted that the increment of local flow rate inside the fiber $\left(q(z+\Delta z)^{-} q(z)\right)$ in a differential fluid element equals to the amount of water permeated into the same differential fluid element $(\mathrm{J}(\mathrm{z}) \pi \mathrm{D} \Delta \mathrm{z})$.

\section{Momentum Balance equations}

The problem dealing with the pressure distribution can be solved by setting up 
momentum balance within the differential length $\Delta z$ of a hollow fiber membrane. For steady-state operation, ${ }^{14}$ the momentum balance equation can be expressed as:

$$
\Delta P=\frac{4 \tau}{\mathrm{d}} \Delta z+\rho\left(\bar{u}(z+\Delta z)^{2}-\bar{u}(z)^{2}\right)
$$

where $\Delta P=P(z+\Delta z)-P(z), \mathrm{P}(\mathrm{z})$ is the local transmembrane pressure, $\tau$ is wall shear stress, $\mathrm{d}$ is inside diameter of fiber, $\rho$ is water density, $\bar{u}(z)=\frac{q(z)}{A}$ denotes the average axial flow velocity inside the fiber at coordinate $\mathrm{z}$, and A is lumen cross-sectional area of fiber.

The shear force $\tau$ for laminar flow in tube is defined as: ${ }^{15}$

$$
\tau=f \frac{\rho \bar{u}^{2}}{2}
$$

where $\mathrm{f}$ is the Fanning frictional factor. It also should be noted that the Fanning frictional factor defined in Eq. (3) is based on the local average velocity $\bar{u}$.

Based on the Newton's law of viscosity, the wall shear stress $\tau$ is given by:

$$
\tau=\mu\left(\frac{\partial u}{\partial r}+\frac{\partial v}{\partial z}\right)
$$

where $\mu$ is water viscosity, $v$ is radial flow velocity. On the assumption that the mass injection through the membrane wall is uniform at each segment $(\Delta \mathrm{z}), \frac{\partial v}{\partial z}$ is zero at each segment and hence can be eliminated from Eq. (4). Thus Eq. (4) becomes:

$$
\tau=\mu \frac{\partial u}{\partial r}
$$

Eq. (6) could be obtained by Substituting Eq. (5) into Eq. (2):

$$
\begin{aligned}
& \frac{\mathrm{d} u}{d r}=-\frac{r}{2 \mu}\left(\frac{\Delta P-\rho \Delta \bar{u}^{2}}{\Delta z}\right) \\
& \Delta \bar{u}^{2}=\bar{u}(z+\Delta z)^{2}-\bar{u}(z)^{2}
\end{aligned}
$$


Revised manuscript AIChE-15-16842R2 for submission to AIChE Journal

For the permeable tube, the different local filtration velocities along fiber result in the different local flow rates and the unsteady flow. ${ }^{18}$ Thus the following boundary conditions can be difined: ${ }^{19}$

$$
\begin{gathered}
\text { at } \mathrm{r}=\mathrm{R}, u=u_{S} \\
\text { at } \mathrm{r}=\mathrm{R}, \frac{d u}{d r}=-\frac{\alpha}{\sqrt{K}}\left(u_{S}-v\right)
\end{gathered}
$$

where $\mathrm{R}$ is the fiber inside radius, $\mathrm{u}_{\mathrm{s}}$ is the slip velocity of membrane wall, $\mathrm{K}$ is the permeability of the membrane, $\alpha$ is dimensionless slip parameter depending on the pore structure of permeable material. ${ }^{19}$

Using boundary conditions of Eq. (8), Eq. (6) can be rewritten:

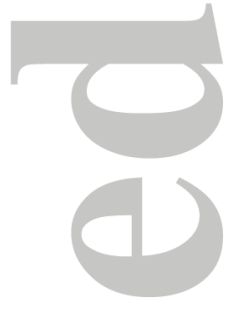

$$
\begin{gathered}
\int_{u}^{u_{S}} d u=\int_{r}^{R}-\frac{r}{2 \mu}\left(\frac{\Delta P-\rho \Delta \bar{u}^{2}}{\Delta z}\right) d r \\
\text { Thus, } u=u_{S}+\frac{\left(R^{2}-r^{2}\right)}{4 \mu} \frac{\left(\Delta P-\rho \Delta \bar{u}^{2}\right)}{\Delta z}
\end{gathered}
$$

In order to solve the unknown parameter $u_{s}$, Eq. (12) can be obtained from Eq. (6) using another boundary conditions of Eq. (9):

$$
u_{S}=v+\frac{R \sqrt{K}}{2 a \mu}\left(\frac{\Delta P-\rho \Delta \bar{u}^{2}}{\Delta z}\right)
$$

The relationship between the axial flow velocity (u) and radial flow velocity (v) can be obtained by combining Eq. (11) and Eq. (12):

$$
u=v+\left(\frac{\left(R^{2}-r^{2}\right)}{4 \mu}+\frac{R \sqrt{K}}{2 a \mu}\right)\left(\frac{\Delta P-\rho \Delta \bar{u}^{2}}{\Delta z}\right)
$$

The average axial velocity of cross-section $(\overline{\mathrm{u}})$ can be calculated from:

$$
\bar{u}=\frac{\int_{0}^{\mathrm{R}} 2 \pi r u d r}{\pi \mathrm{R}^{2}}
$$


Revised manuscript AIChE-15-16842R2 for submission to AIChE Journal

Eq. (15) is obtained by substituting Eq. (13) into Eq. (14):

$$
\frac{\Delta \mathrm{P}}{\Delta Z}-\frac{\rho \Delta \bar{u}^{2}}{\Delta Z}=8 \mu\left(\frac{\bar{u}-v}{R^{2}+4 R \sqrt{K} / \alpha}\right)
$$

The shear stress in hollow fiber membrane is calculated using Eq. (2) and Eq. (15):

$$
\tau=4 R \mu\left(\frac{\bar{u}-v}{R^{2}+4 R \sqrt{K} / \alpha}\right)
$$

Thus, the Fanning frictional factor can be derived from Eq. (3) and Eq. (16):

$$
f=\frac{16}{\operatorname{Re}}\left(\frac{1-2 \frac{\mathrm{Re}_{r}}{\mathrm{Re}}}{1+\frac{4 \sqrt{K}}{\alpha R}}\right)
$$

where

$$
\mathrm{Re}=\frac{d \bar{u} \rho}{\mu}, \quad \operatorname{Re}_{r}=\frac{r v \rho}{\mu}
$$

Here, $R e$ and $\mathrm{Re}_{\mathrm{r}}$ are axial and radial Reynolds number, respectively. It is noted that for the nonporous tube, the permeability $K$ is equal to 0 and the radial Reynolds number $R e_{r}$ is also equal to 0 . Thus, the Fanning frictional factor $f=\frac{16}{\mathrm{Re}}$, which is the dimensionless Fanning frictional factor caused by the fluid flow in the horizontal nonporous tube. ${ }^{15}$

The pressure distribution along the fiber can be obtained from Eqs. (1), (2), (3) and (17):

$$
\Delta P=f \frac{32 \rho \Delta z}{\pi^{2} d^{5}} q(z)^{2}+\frac{32 \rho \pi D \Delta z}{\pi^{2} d^{4}} q(z) J(z)
$$

where the differential length $\Delta \mathrm{z}=\mathrm{L} / \mathrm{N}, \mathrm{L}$ is fiber length, $\mathrm{N}$ is the number of the segments divided along fiber. Thus, Eq. (19) can be rewritten as:

$$
P_{i+1}=P_{i}+f \frac{32 \rho \Delta z}{\pi^{2} d^{5}} q_{i}^{2}+\frac{32 \rho \pi D \Delta z}{\pi^{2} d^{4}} q_{i} J_{i} \quad(i=1,2, \cdots \cdots, N)
$$

On the basis of the resistance-in-series model, the local flux can be calculated by Eq. (21): 
Revised manuscript AIChE-15-16842R2 for submission to AIChE Journal

$$
J(z)=\frac{P(z)}{\mu R_{t}}=\frac{P(z)}{\mu R_{m}}
$$

where $R_{t}$ is total membrane resistance, $R_{m}$ is intrinsic membrane resistance. In the filtration experiments using deionized water, the total membrane resistance $R_{t}$ is equal to the intrinsic membrane resistance $R_{m}$. The intrinsic membrane resistance $R_{m}\left(6 \times 10^{11} \mathrm{~m}^{-1}\right)$ could be determined by filtrating deionized water through virgin hollow fiber membrane of $100 \mathrm{~mm}$ length.

The local flux distribution can be derived from Eqs. (20) and (21):

$$
J_{i+1}=J_{i}+f \frac{32 \rho \Delta z}{\pi^{2} d^{5} \mu R_{m}} q_{i}^{2}+\frac{32 \rho \pi D \Delta z}{\pi^{2} d^{4} \mu R_{m}} q_{i} J_{i} \quad(i=1,2, \cdots \cdots, N)
$$

In order to solve Eq. (22), the following boundary conditions are used:

$$
\begin{gathered}
\left.\frac{d J(z)}{d z}\right|_{z=0}=0 \text { namely } J_{1}=J_{2} \\
q(z)=\int_{0}^{Z} \pi D J(z) d z \text { namely } q_{i}=\sum_{x=1}^{i}\left(\frac{\pi D L}{N} J_{x}\right)(i=2,3, \cdots \cdots, N)
\end{gathered}
$$

Eq. (23) implies that the local flux gradients vanish at the dead-end $(\mathrm{z}=0)$ of the hollow fiber. Eq. (24) means that the local flow rate inside the fiber at $i$ th segment is equal to the sum of the local fluxes of total $i$ segments.

It is noted that there is still an unknown parameter, slip parameter $\alpha$, in the objective Eq. (17) and Eq. (22), which can be evaluated using local flux experimental results as discussed in the following section.

\section{Simulation algorithm}

The procedures to obtain the local flux profile along the fiber are shown in Figure 2. The 
Revised manuscript AIChE-15-16842R2 for submission to AIChE Journal

system of equations is solved by the iterative method using Matlab ${ }^{\circledR}$ software (Mathworks, USA). The local flux distribution is considered as a function of the fiber design characteristics (fiber length, fiber diameter, total membrane resistance) and the operating parameters (average operating flux) in the main program. The procedures to solve model equations are as follows:

1. Starting with an initial value of local flux at dead-end $\mathrm{J}_{1}=0.01 \mathrm{~L} /\left(\mathrm{m}^{2} . \mathrm{h}\right)$. It is noted that the local flux is equal to $0.01 \mathrm{~L} /\left(\mathrm{m}^{2} . \mathrm{h}\right)$, the local flow velocity in the lumen is very small (generally less than $1 \times 10^{-6} \mathrm{~m} / \mathrm{s}$ ) and close to zero. Certainly, the other small value was also suitable for the initial local flux $J_{1}$. However, $J_{1}$ can not be set to 0 . Otherwise, on the basis of boundary condition Eq. (23), all the local fluxes along fiber would be zero and the calculation program would be in endless loop.

2. Calculating the simulated result of local flux $J_{i}$ along fiber by using Eqs. (22) - (24).

3. Comparing the calculated outlet flow $\mathrm{q}_{\mathrm{N}}$ with the setting outlet flow $\mathrm{q}_{\mathrm{e}}\left(q_{e}=\pi D J_{e}\right.$, where $\mathrm{J}_{\mathrm{e}}$ is average operating flux) to estimate error.

4. Continuing from step 1 and increasing the local flux at dead-end $J_{1}$ if the error is not satisfied, Error $=\left|q_{N}-q_{e}\right|<10^{-5}$.

As the flux gradients mainly depend upon these fiber design characteristics and operating parameters, more attention was given to the impact of the fiber length, fiber diameter as well as the average operating flux on local flux distribution along the fiber in this study.

\section{(Insert Figure 2 here)}




\section{Optimization strategy for fiber geometry}

\section{Calculation of production efficiency per footprint}

To optimize the fiber length and diameter, the water production efficiency (Y) of module per footprint was calculated in this study as follows:

$$
Y=\frac{Q}{E}=\frac{Q}{\left[\rho_{o} g\left(L_{w}+L+L_{h}\right)+p_{o}\right] Q_{o}+p_{s} Q}
$$

where $\rho_{o}$ is feed liquid density, $L_{w}$ is the height difference between the air nozzle and fiber end, $L_{h}$ is the distance from the fiber outlet to the liquid level. The total of $L_{w}$ and $L_{h}$ was assumed to be $0.5 \mathrm{~m}$, which is obtained from membrane technology handbook. ${ }^{20} \mathrm{Q}_{\mathrm{o}}$ is aeration rate per unit cross section area of module. $\mathrm{p}_{\mathrm{o}}$ is standard atmospheric pressure and $\mathrm{p}_{\mathrm{s}}$ is suction pressure at the fiber outlet. $\mathrm{E}$ is the energy consumption of submerged membrane system. Q is the flow rate per unit cross section area of module and can be calculated as follows: ${ }^{14}$

$$
Q=\frac{2 \pi \varepsilon D L J_{e}}{\sqrt{3}\left(D+d_{o}\right)^{2}}
$$

Here $d_{0}$ is a distance between two adjacent fibers and assumed to be equal to outside diameter of fiber (D) in this study for simplicity. $\varepsilon$ is area ratio of fiber bundle in total footprint and assumed to be 0.5 , which is obtained from the study of Yoon et al. ${ }^{14}$

\section{Objective function for optimization}

The water production efficiency (Y) was set as the objective function with the constraint

for optimization. The constraint was considered to ensure that the pressure drop in the lumen side of hollow fiber did not go beyond a reasonable value. 
Revised manuscript AIChE-15-16842R2 for submission to AIChE Journal

$$
\left\{\begin{array}{l}
Y=M a x . Y \\
\Delta P_{t} \leq \Delta P_{t p}
\end{array}\right.
$$

where $\Delta \mathrm{P}_{\mathrm{t}}$ and $\Delta \mathrm{P}_{\mathrm{tp}}$ are the real pressure drop and permitted pressure drop in the lumen side of the hollow fiber, respectively. To further elaborate the optimization process, the basic data of input parameters for the process were obtained from membrane technology handbook $^{20}$ and MBR pilot studies, ${ }^{21}$ as listed in Table 1.
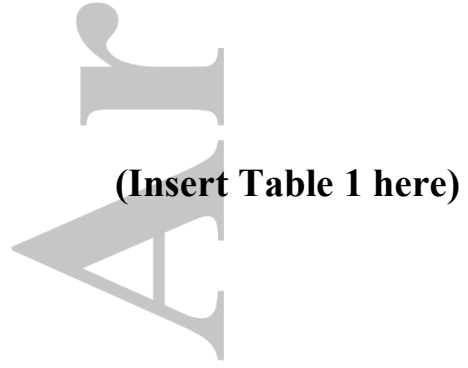

\section{Experimental materials and methods}

\section{Submerged microfiltration system}

Figure $3 \mathrm{a}$ represents the schematic diagram of the submerged hollow fiber membrane filtration system. The assembly consisted of a $5 \mathrm{~L}$ feed tank for storage and supply of the feed solution, feed pump (TP 10-20, Motimo, China), peristaltic pump (BT 100-2J, Longer, China), pressure transducer (1100W, Opine, China), a hotplate/magnetic stirrer (Model 81-2, Sile, China), electronic balance (PL6001-L/01, Mettler Toledo, Switzerland) and a chiller (Model DLSB, Gongyi Yingyu Instrument Co. Ltd., China). The permeate was extracted continuously using a peristaltic pump and recycled back to the feed tank. The liquid inside the tubular test holder was maintained at a constant level by a feed pump and overflow. The inside diameter and length of the tubular test holder were $40 \mathrm{~mm}$ and $1000 \mathrm{~mm}$, respectively. Each module contained only one hollow fiber membrane with length of $1000 \mathrm{~mm}$. The TMP and permeate volume were monitored using a pressure transducer and electronic balance, respectively. The TMP and the flux were recorded by a computer data logging system. 
Revised manuscript AIChE-15-16842R2 for submission to AIChE Journal

\section{The submerged hollow-fiber membrane module}

The submerged hollow-fiber microfiltration membrane module used in the study was made

in the laboratory. In the series of local flux measurement experiments, the hollow fiber membranes with the mean pore size of $0.1 \mu \mathrm{m}$ were made of Polyvinylidene Fluoride (PVDF) with inside and outside diameter of $0.7 \mathrm{~mm}$ and $1.4 \mathrm{~mm}$ (Litree Membrane Technology Co. Ltd., China). Each module contained only one single hollow fiber membrane with length of $1000 \mathrm{~mm}$ and membrane area of $0.0044 \mathrm{~m}^{2}$.

The procedure to make different hollow fiber membrane modules for the local flux measurements is described in the details in our previous study ${ }^{17}$. As shown in Figure $3 \mathrm{~b}$, a single hollow fiber membrane was inserted into two thin polyurethane (PU) hosepipes (intside diameter (d)/outside diameter (D) $=3 \mathrm{~mm} / 4 \mathrm{~mm}$ ), and the interspaces between the fiber and hosepipe were blocked off with epoxy resin. The hollow fiber membrane was divided into three sections - non-working section I, working section and non-working section II. To measure the local flux profile with fiber length of $1000 \mathrm{~mm}$, ten hollow fiber membrane modules with the same working section length of $100 \mathrm{~mm}$ but at different positions along fiber longitudinally were used. Ten hollow fiber membranes were inserted into each individual hose, respectively. The characteristics of these hollow fiber membrane modules for local flux measurement were presented in Table 2. For example, the working section with length of $100 \mathrm{~mm}$ in the hollow fiber membrane module 1 \# located near the upper suction end, whereas the working section in the module 10\# located near the lower suction end. 


\section{(Insert Figure 3 here)}

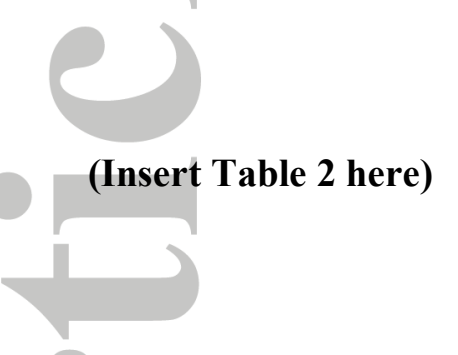

\section{Local flux measurements}

Similarly, the procedure of local flux measurement was described in the details in our previous study ${ }^{17}$ and only a summary was provided here. Before the experiments of local flux measurement, air bubbles inside the lumen of the membrane were removed thorough the following steps: (i) the hollow fiber membranes were soaked in $30 \mathrm{wt} \%$ glycerol and water solution for at least $24 \mathrm{~h}$; (ii) the deionized water was gently injected into the fiber lumen from open-end using a $10 \mathrm{~mL}$ syringe; and (iii) the wetted fiber was then carefully loaded into the membrane module shell with a sealed juncture around the PVC pipes to ensure leak free operation. The temperature of feed solution was maintained at $25.0 \pm 1.0^{\circ} \mathrm{C}$ using a hotplate/magnetic stirrer and a chiller, and measured with a digital thermometer (Model JM222L, Jinming Instrument Co. Ltd., China). Afterwards, the filtration experiments of deionized water were carried out with submerged microfiltration system with constant pressure mode for all these hollow fiber membrane modules (Figure 3a). Permeate was collected in a beaker placed on an electronic balance for permeate monitoring and flux determination through a computer. The measured flux was essentially an average flux value of the working section and was considered as the approximate local flux at the middle point of the working section. All the local flux measurements were 
Revised manuscript AIChE-15-16842R2 for submission to AIChE Journal

repeated three times to confirm the reproducibility of the experimental data.

\section{Results and Discussion}

\section{Parameter calculation and model verification}

To solve the slip parameter $\alpha$, Eq. (17) was changed into a linear equation by taking the logarithm of both sides of the equation:

$$
\ln f=\ln \left(\frac{16}{\operatorname{Re}}\right)+\ln \left(1-2 \frac{\operatorname{Re}_{r}}{\operatorname{Re}}\right)-\ln \left(1+\frac{4 \sqrt{K}}{\alpha R}\right)
$$

In addition, the experimental data used for calculating equation parameter, slip parameter $\alpha$, were obtained from local flux determination experiments at different average operating fluxes of 10 and $15 \mathrm{~L} /\left(\mathrm{m}^{2} . \mathrm{h}\right)$ as listed in Table 3. The Fanning frictional factor (f) on the y-axis was solved using the data of local flux into Eq. (22). Similarly, the axial (Re) and radial $\left(\operatorname{Re}_{\mathrm{r}}\right)$ Reynolds numbers could be obtained using the data shown in Table 3. The known parameters of membrane permeability (K) and fiber inside radius (R) were $1.66 \times 10^{-9} \mathrm{~m} /(\mathrm{s} . \mathrm{Pa})$ and 0.35 $\mathrm{mm}$, respectively. Based on Eq. (28), the experimental data were analyzed and plotted following the linear relationship of $\ln (f)$ and $\ln (16 / R e)+\ln \left(1-2 \mathrm{Re}_{\mathrm{r}} / \mathrm{Re}\right)$ with a correlation coefficient $\mathrm{R}^{2}>0.99$, as shown in Figure 4. Therefore, the coefficient $\left(-\ln \left(1+\frac{4 \sqrt{K}}{\alpha R}\right)\right.$ ) was calculated as 0.35 on the basis of the intercept of the linear regression equation. Finally, the slip parameter $\alpha$ obtained was 0.45 , which is relative to the pore structure or average pore size of the permeable materials. ${ }^{19}$ It should be noted that based on Eq. (17), the fraction factor would increase with an increase on slip parameter, and thus leading to greater pressure drop along the hollow fiber membrane caused by larger flow resistance. 


\section{(Insert Table 3 here)}

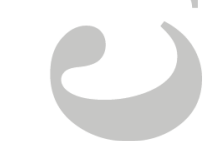

\section{(Insert Figure 4 here)}

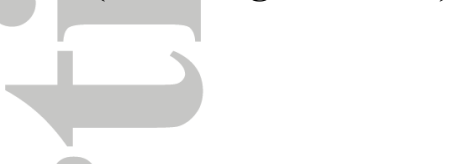

The effect of radial permeate flow on internal flow resistance was taken consideration into the developed model using the slip conditions. To validate the developed model, the simulated suction pressures at the outlet were compared with the experimental data obtained from pure water filtration at different average operating fluxes as shown in Figure 5. The suction pressures under different flux conditions were calculated using Eq. (20). The experimental data taken from the work of Yoon et al. ${ }^{22}$ were employed to validate the proposed model. The model parameters and physical properties used for predicting experimental data of Yoon et al. ${ }^{22}$ were given in Table 4. For comparison, the predicted results from Chang's model ${ }^{7}$ based on the Hagen-Poiseuille theory were also incorporated in Figure 5. It can be found in Figure 5 that the experimental and simulated suction pressures increased linearly with the increase of averaged operating flux. In addition, the predictions using the proposed model in our study were in more accordant with the experimental results than that using Chang's model based on the Hagen-Poiseuille theory.

As shown in Figure 5, an interesting phenomenon is that the simulated suction pressures using the proposed model were almost same as those using Chang's model at the low average operating flux $\left(<5 \mathrm{~L} /\left(\mathrm{m}^{2} \cdot \mathrm{h}\right)\right)$. However, at the high average operating flux, the predictions using the proposed model were obviously larger than those using Chang's model. For 
example, when the operating flux was $22.8 \mathrm{~L} /\left(\mathrm{m}^{2} . \mathrm{h}\right)$, the deviation between the experimental suction pressure and simulation calculated by Chang's model $(12.8 \%)$ was higher than that $(1.1 \%)$ calculated by the developed model in this study. In addition, the deviation between the proposed model and Chang's model increased with the increase of average operating flux. The deviation is ascribed to the flow resistance resulting from the transmembrane flow which increases with the increase of averaged operating flux. ${ }^{18}$ The results confirmed that the model developed in this study was able to predict accurately the relationship between the average operating flux and suction pressure.

(Insert Table 4 here)

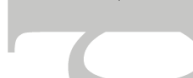

\section{(Insert Figure 5 here)}

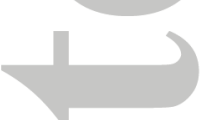

\section{Predicting influence of process parameter on local flux distribution}

As an important parameter of fiber geometry, fiber length affects not only water production but also aeration efficiency. ${ }^{23}$ Thus, the model developed was further used to investigate the effects of fiber length, average operating flux and inside diameter of fiber on local flux distribution.

The local flux profiles of the submerged hollow fiber membrane with different length of $1.0,1.5$ and $2.0 \mathrm{~m}$ at the same constant average operating flux of $10 \mathrm{~L} /\left(\mathrm{m}^{2} . \mathrm{h}\right)$ and fiber inside/outside diameter of $0.7 / 1.4 \mathrm{~mm}$ are presented in Figure 6 . It can be seen that the local flux difference between both ends of the fiber increased from 10.0 to $28.2 \mathrm{~L} /\left(\mathrm{m}^{2} . \mathrm{h}\right)$ with the 
increase of the fiber length from 1.0 to $2.0 \mathrm{~m}$, which indicated that under the same average operating flux, the longer fiber could result in more non-uniform local flux profile. This is because the longer fiber could lead to the greater pressure drop per unit length caused by larger flow resistance. ${ }^{7,24}$ Thus, although the longer modules with larger membrane areas can contribute to more water production, an increase in fiber length led to more non-uniform local flux distribution and more severe membrane fouling. To better understand the local permeability of fiber, the investigation on the effect of average operating flux and fiber inside diameter on local flux profiles of $2.0 \mathrm{~m}$ - length fiber was conducted.

\section{(Insert Figure 6 here)}
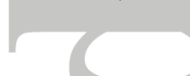

As the average operating flux in the submerged hollow fiber membrane filtration is a significant operating parameter and highly related to the stability of system and the capital costs, ${ }^{25}$ the effect of the average operating flux at 10,15 and $20 \mathrm{~L} /\left(\mathrm{m}^{2} . \mathrm{h}\right)$ on the local flux distribution was investigated as shown in Figure 7. It can be observed from Figure 7 that the local flux along the fiber increased with the increase of the average operating flux. At the same time, the local flux difference between both ends of the fiber increased from 28.5 to $56.5 \mathrm{~L} /\left(\mathrm{m}^{2} . \mathrm{h}\right)$ with an increase in the average operating flux from 10 to $20 \mathrm{~L} /\left(\mathrm{m}^{2} . \mathrm{h}\right)$, suggesting that the asymmetry distribution of the flux along the fiber intensified with the increase of the imposed flux.

It also can be seen in Figure 7 that the maximum local flux at the open-end increased significantly from 30.9 to $62.1 \mathrm{~L} /\left(\mathrm{m}^{2} . \mathrm{h}\right)$ with the increase of the imposed flux from 10 to 20 
$\mathrm{L} /\left(\mathrm{m}^{2} . \mathrm{h}\right)$. However, the local flux obtained at the dead-end changed slightly. This phenomenon is ascribed to the pressure drop in fiber lumen. ${ }^{5}$ A large driving force generated at a high flux during the operating could lead to a large pressure drop due to the increase of the flow resistance. ${ }^{24}$ Thus, the increase of the average operating flux slightly impacted the local flux near the dead-end.

\section{(Insert Figure 7 here)}

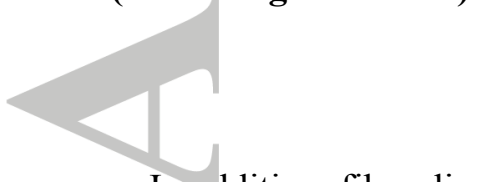

In addition, fiber diameter as a significant fiber geometry parameter affects packing density of module and the hydrodynamics of fiber lumen. Hence, it is essential to investigate the effect of fiber diameter on the local flux distribution. Figure 8 presents the local flux distribution along the fibers with different inside diameters of $0.5,0.7$ and $0.9 \mathrm{~mm}$ at the same conditions including average operating flux of $10 \mathrm{~L} /\left(\mathrm{m}^{2} . \mathrm{h}\right)$, fiber length of $2.0 \mathrm{~m}$ and ratio of inside and outside diameter of 1:2.

As can be seen in Figure 8, the local flux difference between both ends of the fiber increased significantly from 18.2 to $46.0 \mathrm{~L} /\left(\mathrm{m}^{2} . \mathrm{h}\right)$ with the decrease of fiber inside diameter from 0.9 to $0.5 \mathrm{~mm}$, indicating the asymmetry distribution of the local flux along the fiber intensified with the decrease of fiber inside diameter. Furthermore, an interesting phenomenon was observed that the local flux of the fiber with inside diameter of $0.5 \mathrm{~mm}$ at the dead-end was approximately close to zero, which implied that there existed an effective working length of the submerged hollow fiber membrane at a certain operating condition. The reason was that the longer and thinner hollow fiber membrane suffered from more severe 
filtration resistance and fluid resistance when the fluid flowed through the fiber lumen under a certain imposed flux, thus leading to a lower driving force near the dead-end. ${ }^{26}$ Therefore, the optimization of fiber geometry is great significance of the stable operation of submerged hollow fiber membrane system.

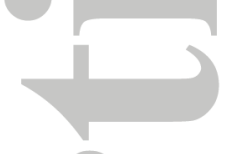

\section{(Insert Figure 8 here)}

\section{Optimization of fiber geometry}

To fully evaluate the effect of fiber geometry on productivity, the effects of fiber length and diameter on the water production efficiency with different average operating fluxes of 10, 15, 20 and $25 \mathrm{~L} /\left(\mathrm{m}^{2} . \mathrm{h}\right)$ were predicted and presented in Figure 9. As shown in Figure 9, the growth rate of water production efficiency for the fiber with small inside diameter was larger than that for the fiber with large inside diameter as increasing fiber length at any operating flux when fiber length was less than $2.0 \mathrm{~m}$. It can be seen in Figure 9a that the water production efficiency increased firstly and then reached the stable state with the increase of fiber length when fiber inside diameter was at the range of $0.5-0.7 \mathrm{~mm}$. However, the water production efficiency increased gradually and monotonously with increasing fiber length when fiber inside diameter was at the range of 0.7-1.0 $\mathrm{mm}$.

Similarly, when the averaged operating flux increased to $15 \mathrm{~L} /\left(\mathrm{m}^{2} . h\right)$, the water production efficiency increased firstly and then decreased with increasing the fiber length when fiber inside diameter was at the range of 0.5-0.7 mm, whereas it increased firstly and finally reached a plateau when fiber inside diameter was at the range of 0.7-1.0 $\mathrm{mm}$ (Figure 
Revised manuscript AIChE-15-16842R2 for submission to AIChE Journal

9b). In addition, this trend was more obvious when the averaged operating flux was carried out with 20 and $25 \mathrm{~L} /\left(\mathrm{m}^{2} . \mathrm{h}\right)$ (Figures $9 \mathrm{c}$ and $\left.9 \mathrm{~d}\right)$. For example, as the fiber diameter was 0.5 $\mathrm{mm}$, the maximum water production efficiency obtained at different averaged operating fluxes of 15, 20 and $25 \mathrm{~L} /\left(\mathrm{m}^{2} . \mathrm{h}\right)$ was $4.9,5.0$ and $5.2 \mathrm{~m}^{3} / \mathrm{kWh}$, and the corresponding fiber length was 2.1, 1.9 and $1.6 \mathrm{~m}$, respectively. There are two reasons: One is the thinner and longer fibers can lead to high packing density. ${ }^{7}$ For filtration at constant flux, the high packing density could increase the permeate flow rate per unit cross section area. The other is the thinner and longer fibers may lead to a higher immersion depth of module and greater axial pressure drop, which implies that more energy is needed for aeration and permeate suction. ${ }^{14}$ The analysis indicated that there is an optimal fiber length for a given fiber inside diameter and averaged operating flux. Therefore, it is necessary to choose optimal fiber geometry with compromised performance of specific energy consumption and permeation flux.

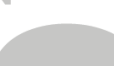

\section{(Insert Figure 9 here)}

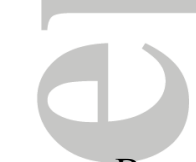

Based on the Eq. (27) used as the objective function for optimization, the optimum fiber length and the corresponding water production efficiency with varying average operating flux and fiber inside diameter are presented in Figure 10. It can be seen in Figure 10a that the optimum fiber length increased monotonously with the increase of fiber inside diameter and decrease of averaged operating flux. For example, the optimum length increased from 0.5 to $2.4 \mathrm{~m}$ when the averaged operating flux and fiber inside diameter changed from 25 
$\mathrm{L} /\left(\mathrm{m}^{2} . \mathrm{h}\right)$ and $0.5 \mathrm{~mm}$ to $10 \mathrm{~L} /\left(\mathrm{m}^{2} . \mathrm{h}\right)$ and $1.0 \mathrm{~mm}$, respectively. The reason was that the thinner fiber at higher operating flux results in significant pressure drop along fiber. ${ }^{7}$ However, the corresponding water production efficiency increased with the increase of both averaged operating flux and fiber inside diameter as shown in Figure 10b.

By closely scrutinizing Figure 10a and b, it was noted that regardless of the changes of average operating flux, the optimum fiber length and the corresponding water production efficiency increased simultaneously with increase of fiber inside diameter. For example, the optimum fiber length increased from 0.6 to $1.6 \mathrm{~m}$ and the corresponding water production efficiency increased from 3.0 to $3.8 \mathrm{~m}^{3} / \mathrm{kWh}$ at the constant averaged operating flux of 20 $\mathrm{L} /\left(\mathrm{m}^{2} . \mathrm{h}\right)$ with the increase of fiber inside diameter from 0.5 to $1.0 \mathrm{~mm}$. Therefore, while for a given operating flux used, a reasonable long fiber length and big fiber diameter is favorable in order to increase the water production efficiency.
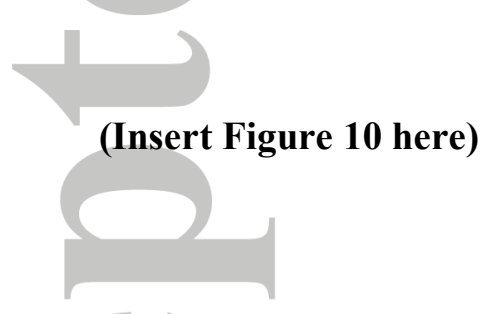

\section{Conclusions}

A filtration mathematical model was successfully developed by complete mass balance and momentum balance to predict the local flux distribution along fiber and optimize the fiber geometry. The effect of radial permeate flow on flow resistance was taken into consideration in the model. It was found that there existed an effective working length of the submerged hollow fiber membrane at certain operating conditions. The simulated results were in more accordant with the literature data than those obtained by the traditional 
Revised manuscript AIChE-15-16842R2 for submission to AIChE Journal

model based on the Hagen-Poiseuille theory. Furthermore, the asymmetry distribution of the local flux along the fiber intensified with increase of the average operating flux and fiber length, but decreased with increase of fiber inside diameter. Moreover, the developed model coupled with energy consumption analysis could efficiently predict and illustrate the relationship between fiber geometry and water production efficiency. The simulation suggested that a reasonable long fiber length and large fiber diameter is beneficial to increasing water production efficiency at certain averaged operating flux.

\section{Acknowledgments}

This work was financially supported by Chang-jiang Scholars and Innovative Research

Team in the University of Ministry of Education of China (Grant No. IRT13084) and the Commonweal Project of China National Ocean Bureau (No. 201105025).

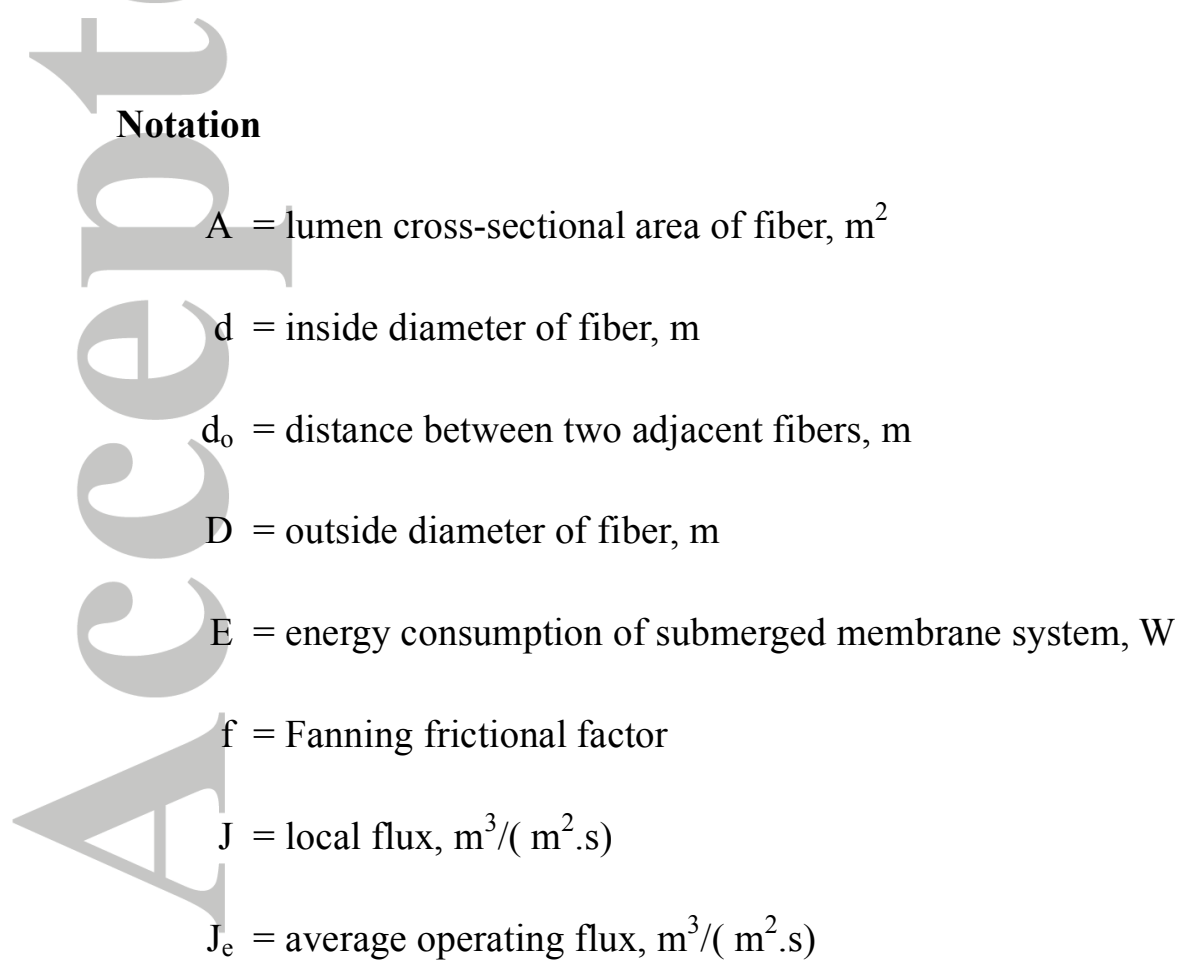


Revised manuscript AIChE-15-16842R2 for submission to AIChE Journal

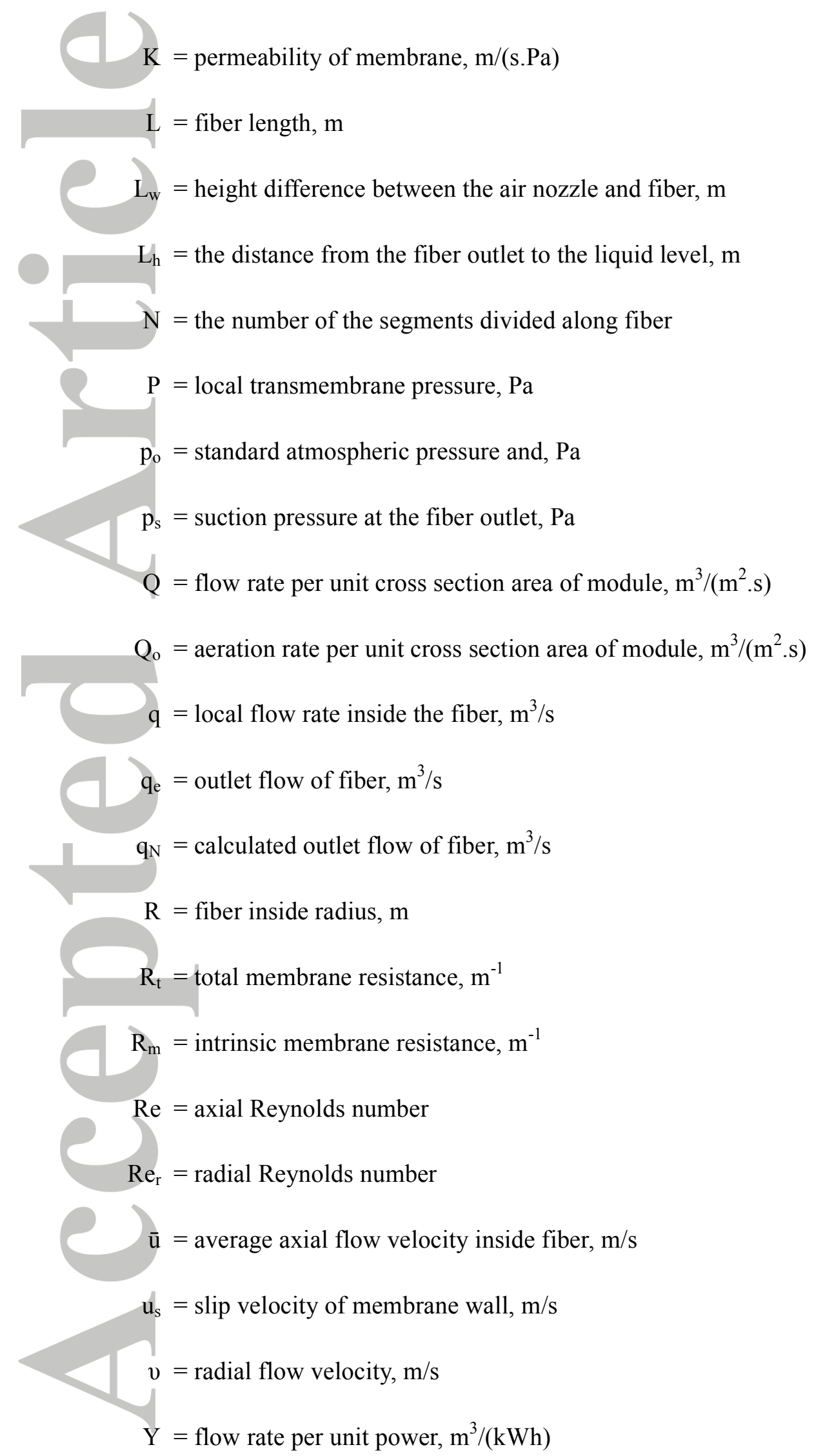




\section{Greek Letters}

$\alpha=$ slip parameter

$\Delta \mathrm{P}_{\mathrm{t}}=$ real pressure drop in the lumen side of the hollow fiber, $\mathrm{kPa}$

$\Delta \mathrm{P}_{\mathrm{tp}}=$ permitted pressure drop in the lumen side of the hollow fiber, $\mathrm{kPa}$

$\varepsilon=$ area ratio of fiber bundle in total footprint

$\mu=$ water viscosity, Pa.s

$\mu_{\mathrm{o}}=$ feed liquid viscosity, Pa.s

$\rho=$ water density, $\mathrm{kg} / \mathrm{m}^{3}$

$\rho_{\mathrm{o}}=$ feed liquid density, $\mathrm{kg} / \mathrm{m}^{3}$

$\tau=$ wall shear stress, $\mathrm{N}$

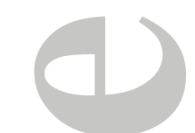

\section{Literature Cited}

1. Tian JY, Liang H, Nan J, Yang YL, You SJ, Li GB. Submerged membrane bioreactor (sMBR) for the treatment of contaminated raw water. Chem. Eng. J. 2009;148:296-305.

2. Phattaranawik J, Fane AG, Pasquier ACS, Wu B. Membrane bioreactor with bubble-size transformer: Design and fouling control. AIChE J. 2007;53:243-248.

3. Meng FG, Liao BQ, Liang SA, Yang FL, Zhang HM, Song LF. Morphological visualization, componential characterization and microbiological identification of membrane fouling in membrane bioreactors (MBRs). J. Membr. Sci. 2010;361:1-14.

4. Giménez B, Robles A, Carretero L, Durán F, Ruano MV, Gatti MN, Ribes J, Ferrer J, 
Revised manuscript AIChE-15-16842R2 for submission to AIChE Journal

Seco A. Experimental study of the anaerobic urban wastewater treatment in a submerged hollow-fibre membrane bioreactor at pilot scale. Bioresour. Technol. 2011;102:8879-8806.

5. Chang S, Fane AG. The effect of fiber diameter on filtration and flux distribution-relevance to submerged hollow fiber modules. J. Membr. Sci. $2001 ; 184: 221-231$.

6. Mendret J, Guigui C, Schmitz P. An optical method for in situ characterization of fouling during filtration. AIChE J. 2007;53:2265-2274.

7. Chang S, Fane AG, Vigneswaran S. Modeling and optimizing submerged hollow fiber membrane modules. AIChE J. 2002;48:2203-2212.

8. Chang S, Fane AG, Waite TD. Analysis of constant permeate flow filtration using dead-end hollow fiber membranes. J. Membr. Sci. 2006;268:132-141.

9. Petsev DN, Starov VM, Ivanov IB. Concentrated dispersions of charged colloidal particles: sedimentation, ultrafiltration and diffusion. Colloids Surf A Physicochem Eng Asp. 1993;81:65-81.

10. Liu LY, Ding AW, Lu Y, Ma RY. Modeling the bubbling enhanced microfiltration for submerged hollow fiber membrane module. Desalination. 2010;256:77-83.

11. Lee HM, Lee CH, Chung KY, Lee SH. Prediction model for transmembrane pressure in a submerged hollow-fiber microfiltration membrane. Sep. Sci. Technol. 2004;39:1833-1856.

12. Lee SH, Park PK, Kim JH, Yeon KM, Lee CH. Analysis of filtration characteristics in submerged microfiltration for drinking water treatment. Water Res. 
Revised manuscript AIChE-15-16842R2 for submission to AIChE Journal

$2008 ; 42 ; 3109-3121$.

13. Kinčl J, Doleček P, Cakl J. Filtration model for hollow fiber membranes with compressible cake formation. Desalination. 2009;240:99-107.

14. Yoon SH, Kim HS, Yeom IT. Optimization model of submerged hollow fiber membrane modules. J. Membr. Sci. 2004;234:147-156.

15. Yeh HM. Exponential model analysis of permeate flux for ultrafiltration in hollow-fiber modules by momentum balance. Chem. Eng. J. 2009;147:202-209.

16. Kim AS, Lee YT. Laminar flow with injection through a long dead-end cylindrical porous tube: application to a hollow fiber membrane. AIChE J. 2011;57:1997-2006.

17. Li XH, Li JX, Wang J, Wang H, He BQ, Zhang HW, Guo WS, Ngo HH. Experimental investigation of local flux distribution and fouling behavior in double-end and dead-end submerged hollow fiber membrane modules. J. Membr. Sci. 2014;453:18-26.

18. Hilke R, Albrecht W, Weigel Th, Paul D, Witte S, Hapke J. The duomodule. Part 1: Hydrodynamic investigations. J. Membr. Sci. 1999;154:183-194.

19. Beavers GS, Joseph DD. Boundary conditions at a naturally permeable wall, J. Fluid Mech. 1967;30:197-207.

20. S. Judd. The MBR Book - Principles and Applications of Membrane Bioreactors in Water And Wastewater Treatment, Elsevier, 2006.

21. Di Bella G, Torregrossa M, Viviani G. The role of EPS concentration in MBR foaming: Analysis of a submerged pilot plant. Bioresour. Technol. 2011;102:1628-1635.

22. Yoon SH, Lee SH, Yeom IT. Experimental verification of pressure drop models in hollow fiber membrane. J. Membr. Sci. 2008;310:7-12. 
Revised manuscript AIChE-15-16842R2 for submission to AIChE Journal

23. Chang S, Fane AG. Filtration of biomass with laboratory-scale submerged hollow fibre modules - effect of operating conditions and module configuration. J. Chem. Technol. Bioteehnol. 2002;77:1030-1038.

24. Carroll T, Booker NA. Axial features in the fouling of hollow-fiber membranes. $J$. Membr. Sci. 2000;168:203-212.

25. Field RW, Pearce GK. Critical, sustainable and threshold fluxes for membrane filtration with water industry applications. Adv. Colloid Interface Sci. 2011;164:38-44.

26. Carroll T. The effect of cake and fiber properties on flux declines in hollow-fiber microfiltration membranes. J. Membr. Sci. 2001;189:167-178.

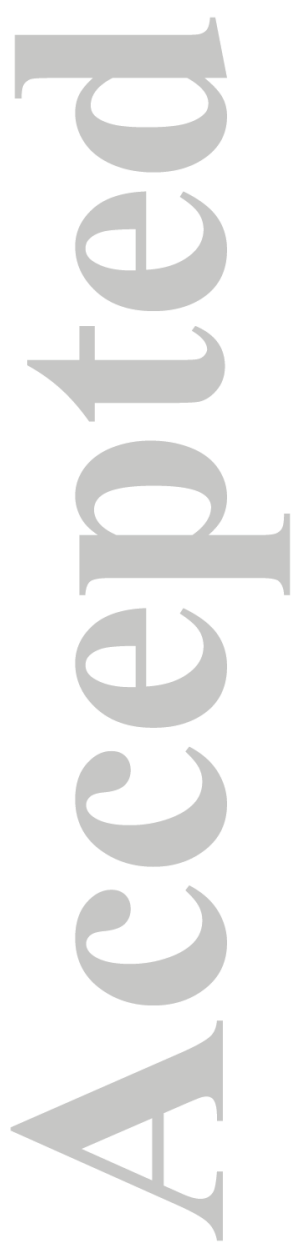


Captions of Figures

Figure 1. Schematic of a single submerged hollow fiber membrane for deionized water filtration modeling.

Figure 2. Flow chart of the solution method for model equations.

Figure 3. The diagrams of (a) submerged hollow fiber membrane filtration system and (b) the single hollow fiber membrane module for local flux measurement.

Figure 4. Relationship between $\ln (f)$ vs. $\ln (16 / R e)+\ln \left(1-2 R e_{r} / R e\right)$ with the best fit.

Figure 5. Comparison between the experimental suction pressures ${ }^{22}$ and those calculated by the proposed model and Chang's model. ${ }^{7}$

Figure 6. The effect of fiber length on local flux distribution along the fiber at the constant average operating flux of $10 \mathrm{~L} /\left(\mathrm{m}^{2} . h\right)$ and fiber inside/outside diameter of $0.7 / 1.4 \mathrm{~mm}$.

Figure 7. The effect of average operating flux on local flux distribution along the fiber at the fiber length of $2.0 \mathrm{~m}$ and fiber inside/outside diameter of $0.7 / 1.4 \mathrm{~mm}$.

Figure 8. The effect of fiber inside diameter on local flux distribution along the fiber at the constant average operating flux of $10 \mathrm{~L} /\left(\mathrm{m}^{2} . \mathrm{h}\right)$, fiber length of $2.0 \mathrm{~m}$ and ratio of inside and outside diameter of 1:2.

Figure 9. The effect of fiber length and diameter on the water production efficiency at the constant average operating flux of (a) $10 \mathrm{~L} /\left(\mathrm{m}^{2} . h\right)$, (b) $15 \mathrm{~L} /\left(\mathrm{m}^{2} . h\right)$, (c) 20 $\mathrm{L} /\left(\mathrm{m}^{2} . h\right)$ and (d) $25 \mathrm{~L} /\left(\mathrm{m}^{2} . h\right)$, respectively.

Figure 10. (a) The optimum fiber length and (b) the corresponding water production efficiency with varying average operating flux and fiber inside diameter. 

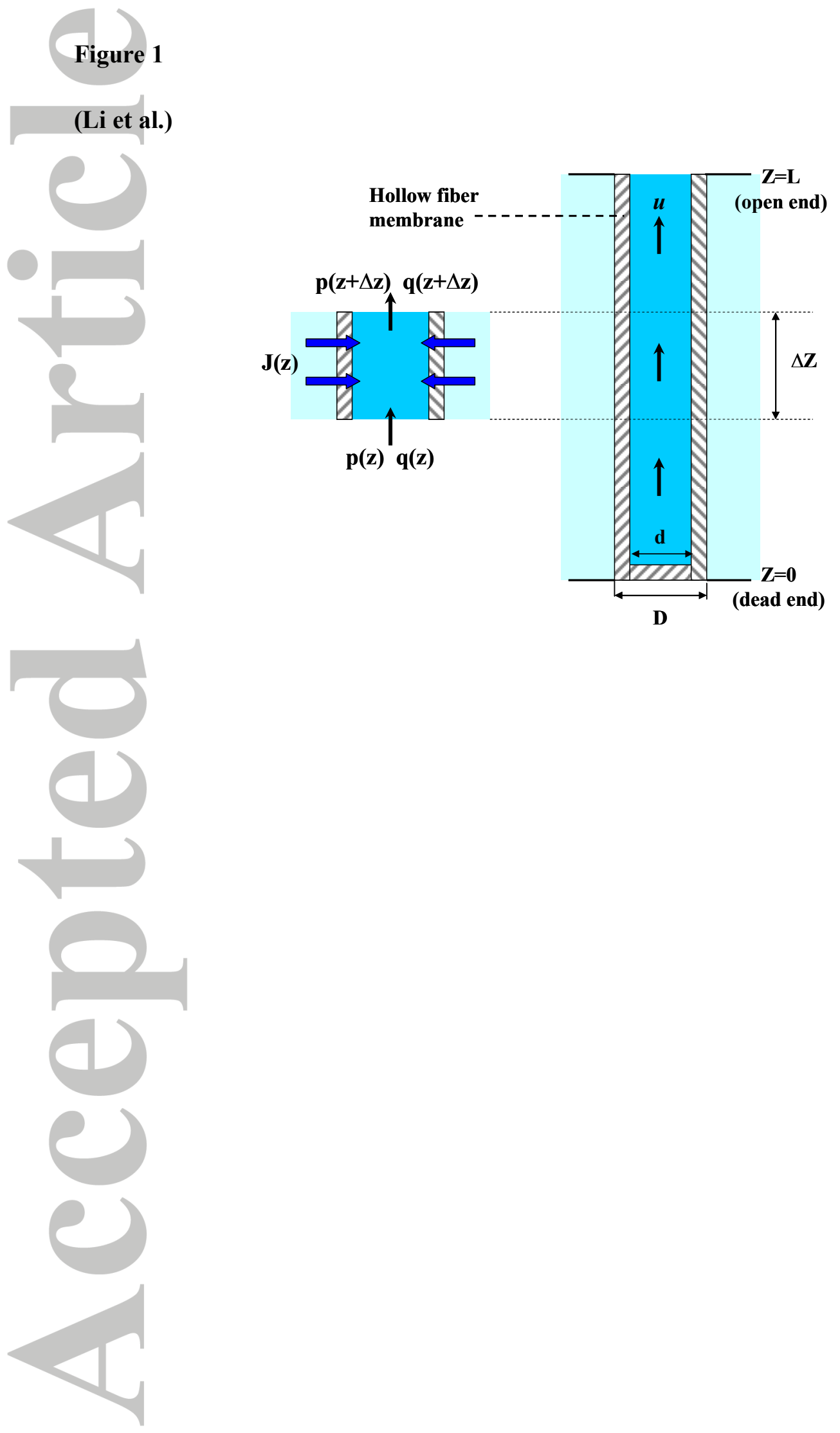

AlChE Journal

This article is protected by copyright. All rights reserved. 


\section{Figure 2}

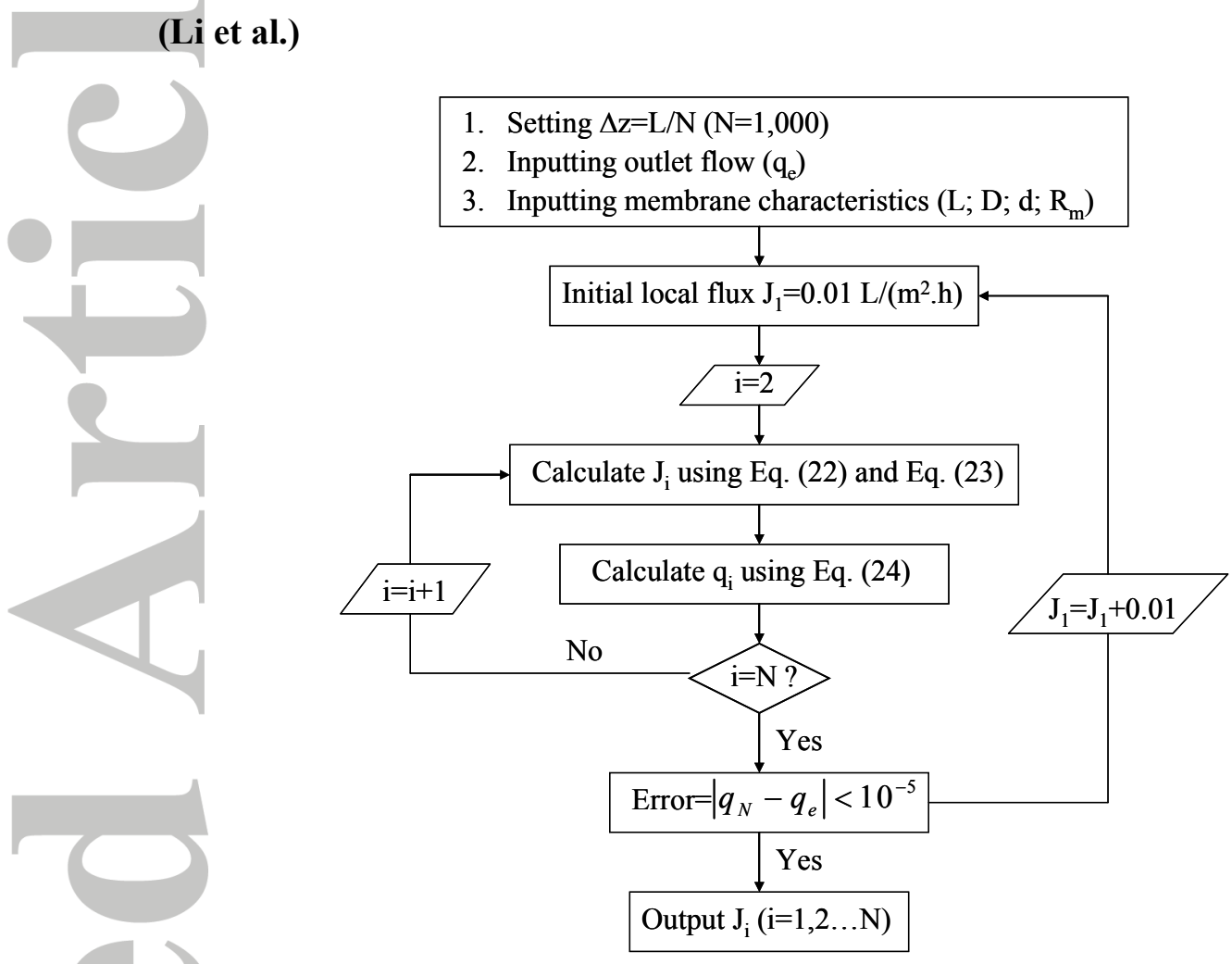

AIChE Journal

This article is protected by copyright. All rights reserved. 


\section{Figure 3}

\section{(Li et al.)}

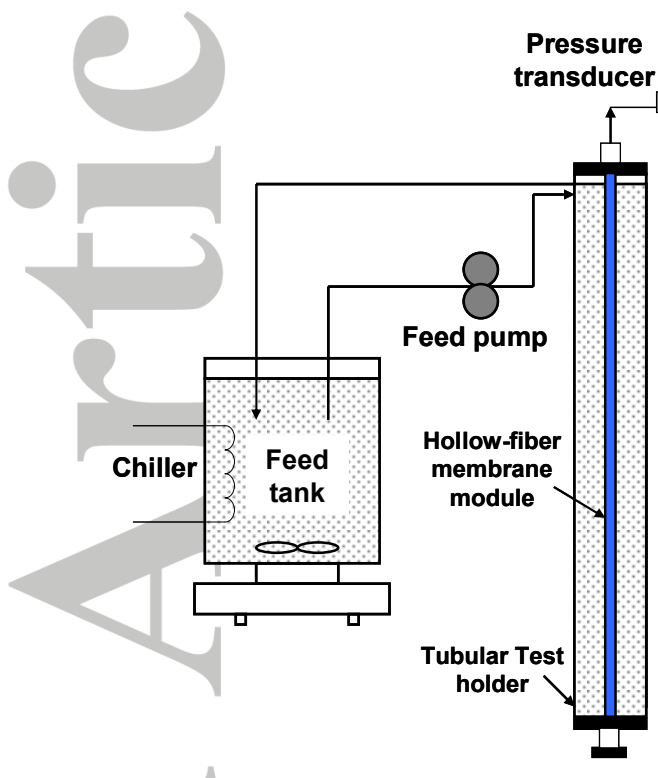

(a)

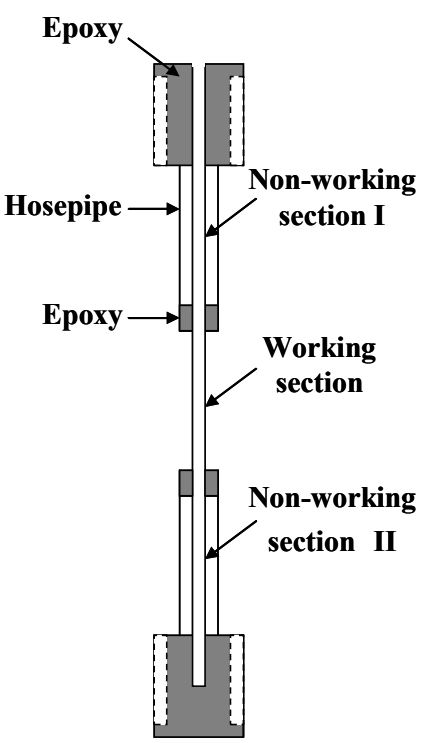

(b) 


\section{Figure 4}

\section{(Li et al.)}
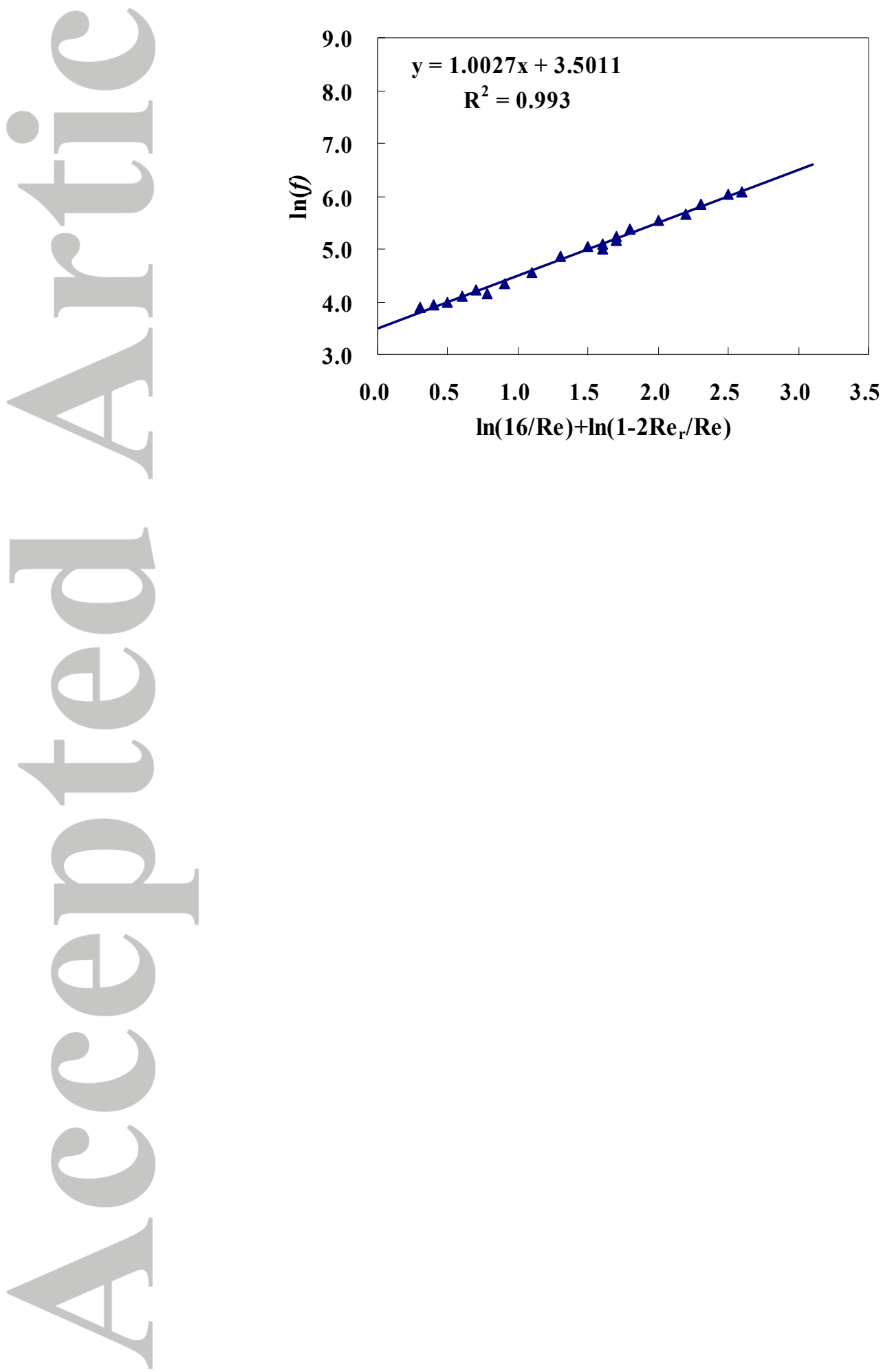

AIChE Journal

This article is protected by copyright. All rights reserved. 

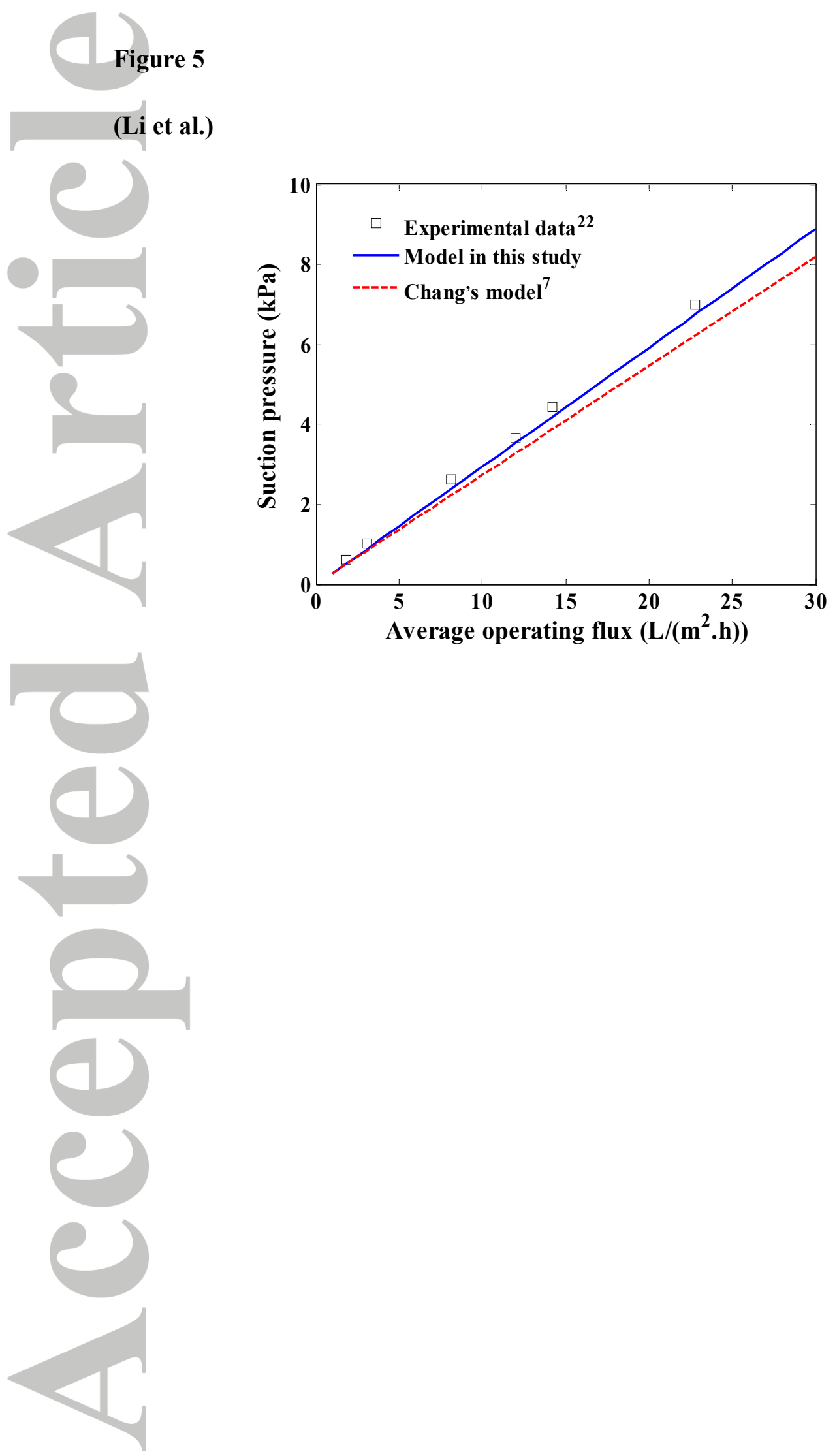

AIChE Journal

This article is protected by copyright. All rights reserved. 


\section{Figure 6}

(Li et al.)
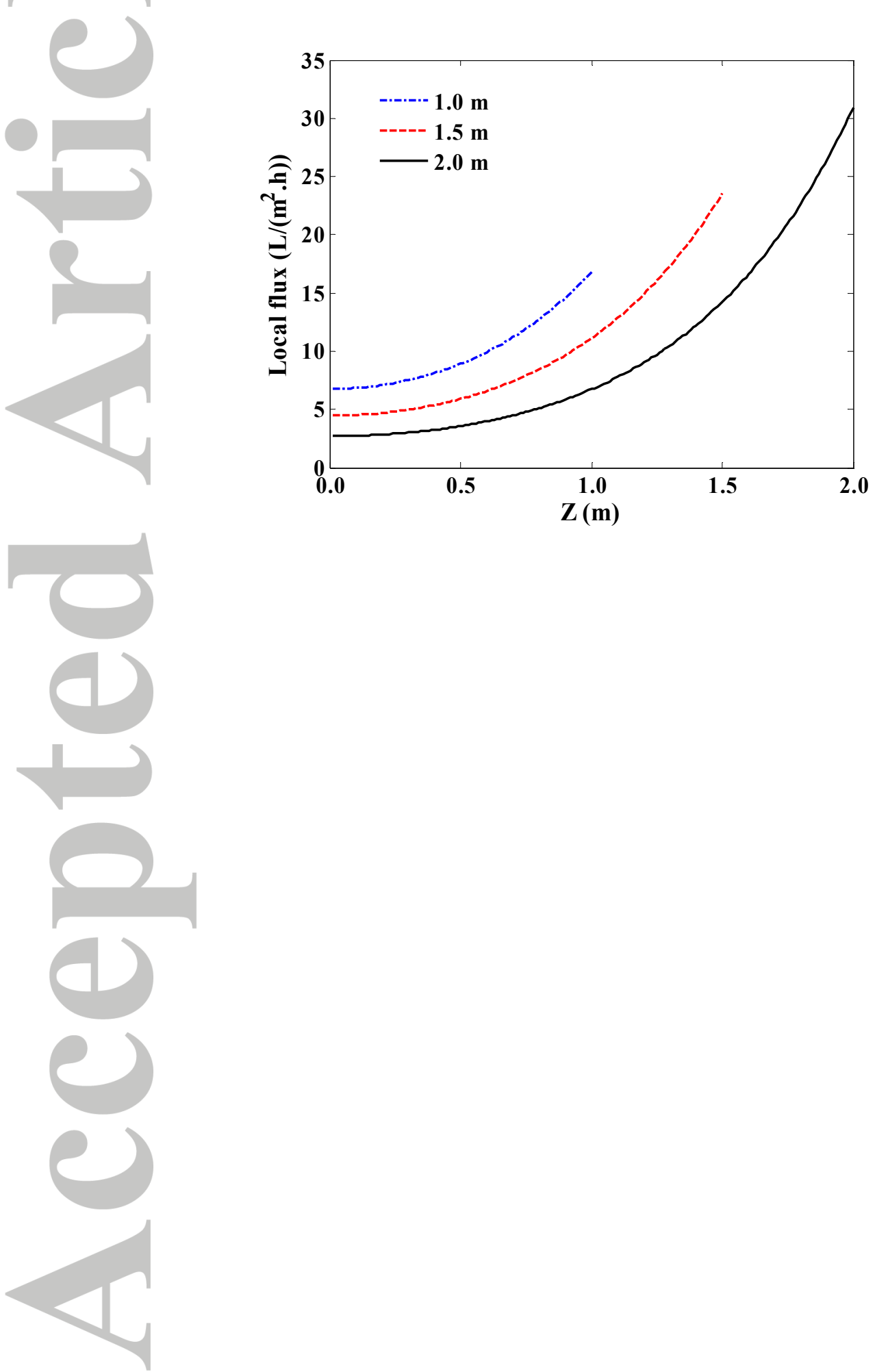

AIChE Journal

This article is protected by copyright. All rights reserved. 

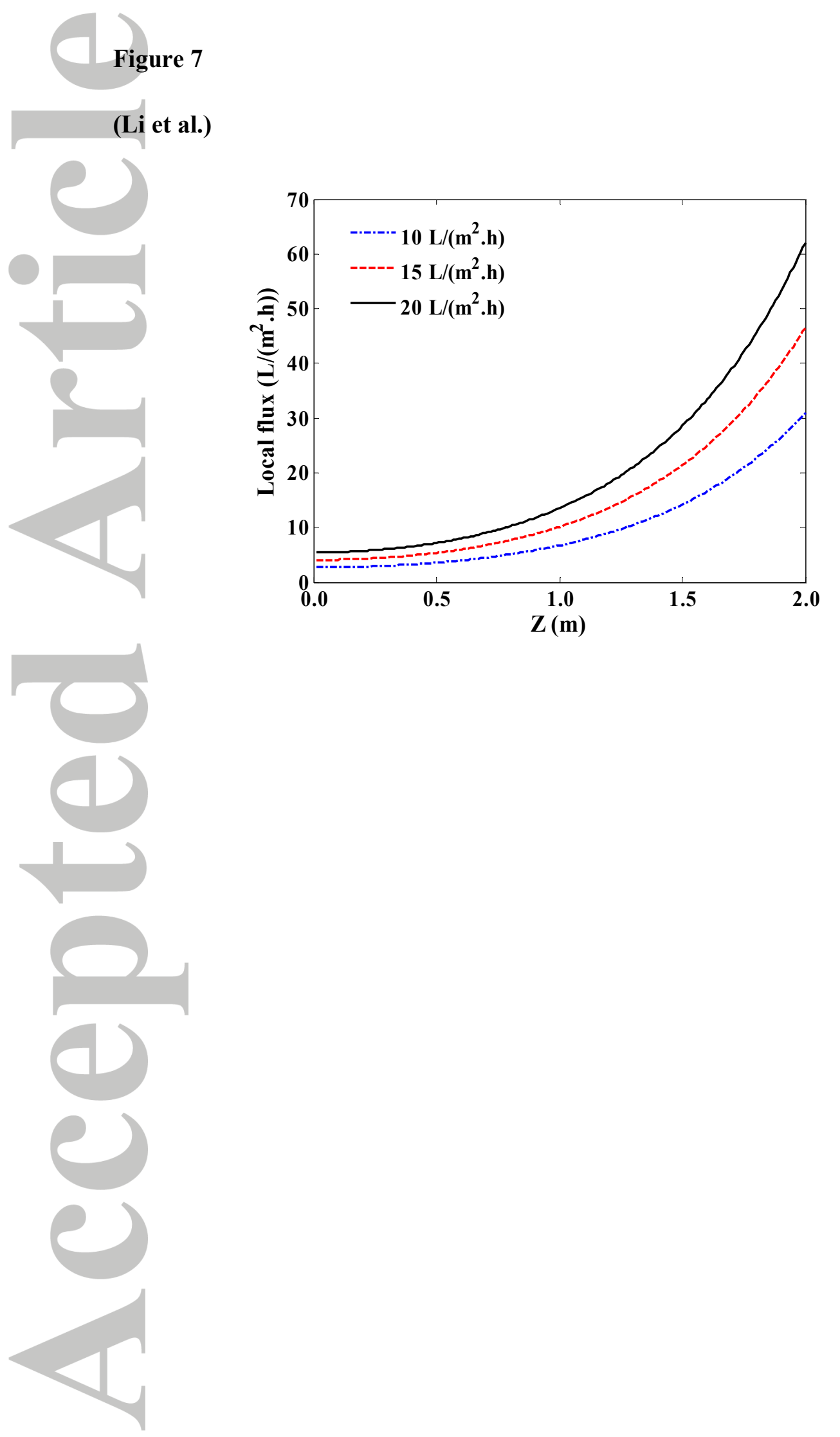

AIChE Journal

This article is protected by copyright. All rights reserved. 


\section{Figure 8}

\section{(Li et al.)}
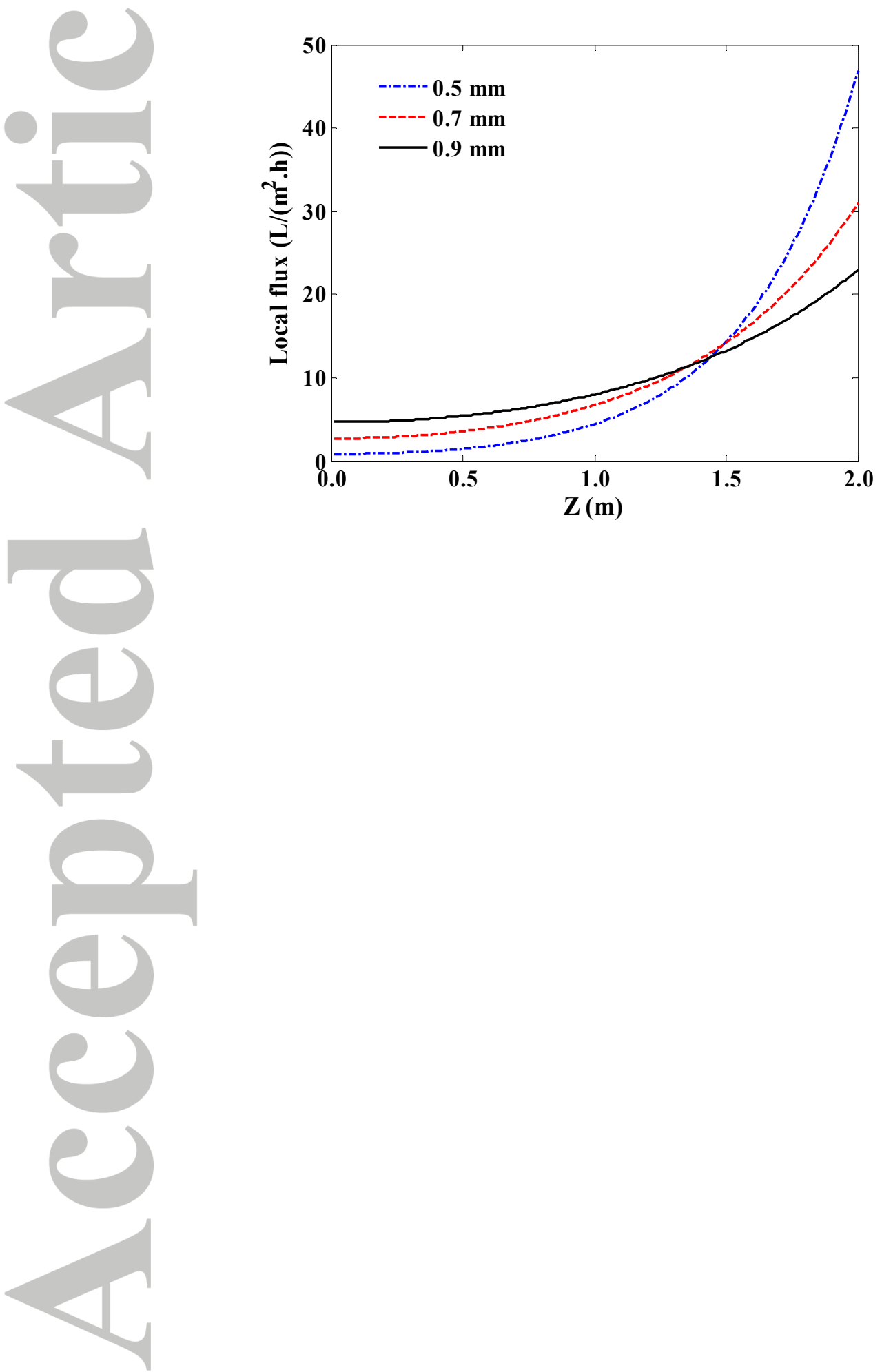

AIChE Journal

This article is protected by copyright. All rights reserved. 


\section{Figure 9}

\section{(Li et al.)}

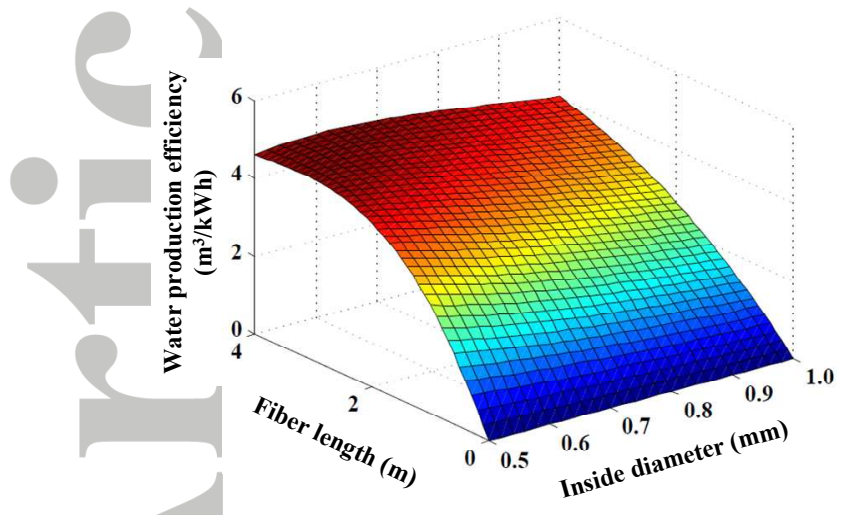

(a)

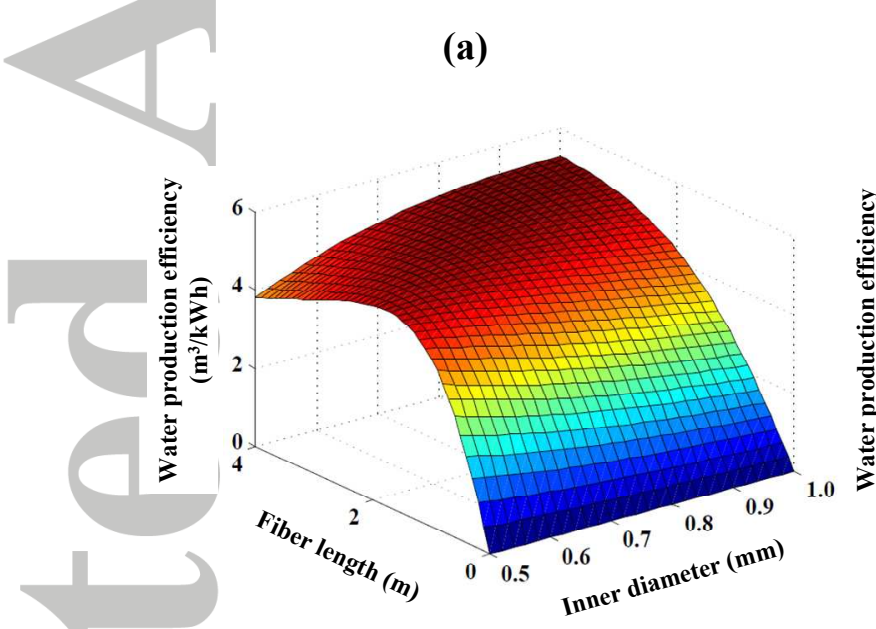

(c)

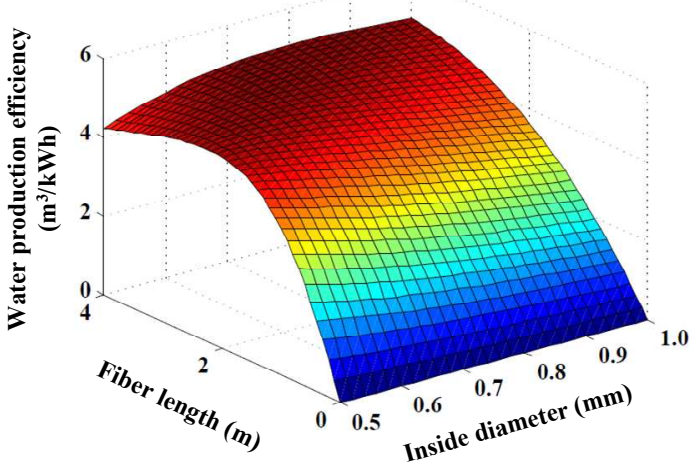

(b)

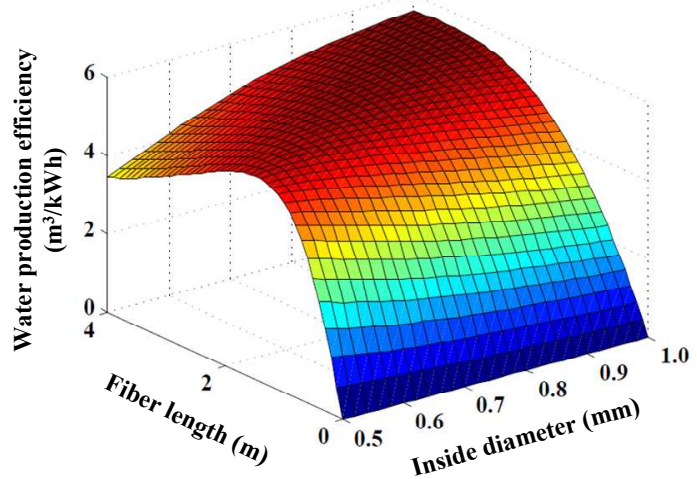

(d) 


\section{Figure 10}

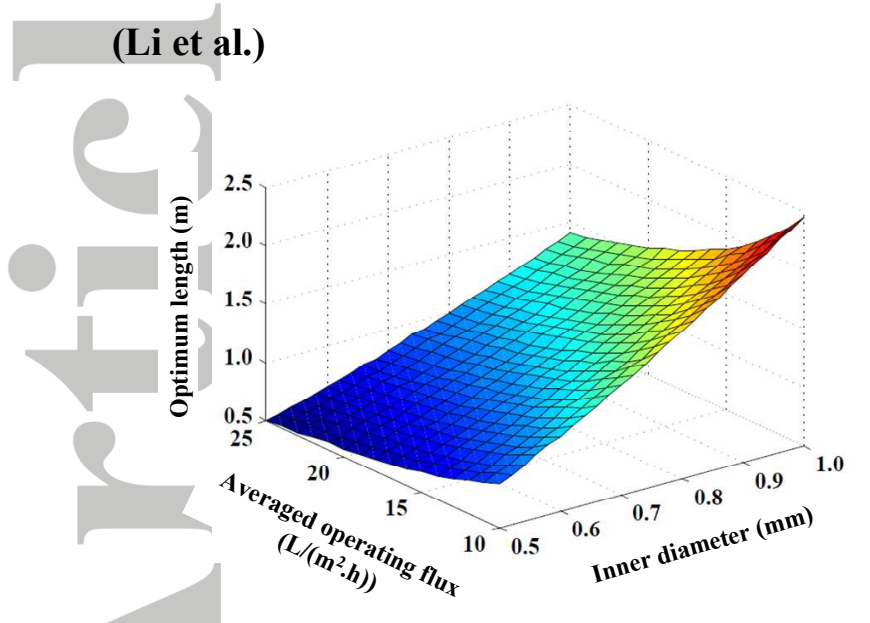

(a)

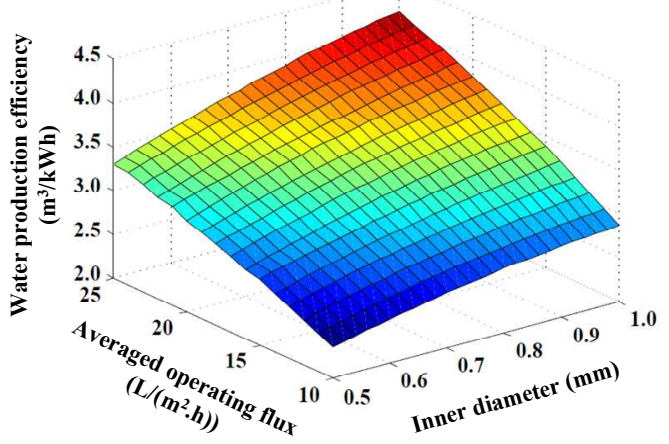

(b)

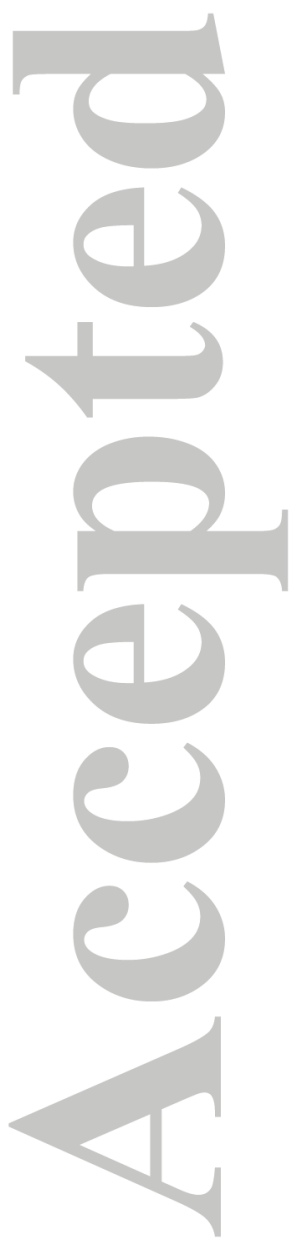




\section{Captions of Tables}

Table 1. Input parameters for fiber optimization analysis

Table 2. Characteristics of the submerged hollow fiber membrane modules for local flux measurement

Table 3. The results of the experimental local fluxes along the fiber at different average operating fluxes of 10 and $15 \mathrm{~L} /\left(\mathrm{m}^{2} . h\right)$

Table 4. Model parameters and physical properties for experimental system of Yoon et al. $^{22}$

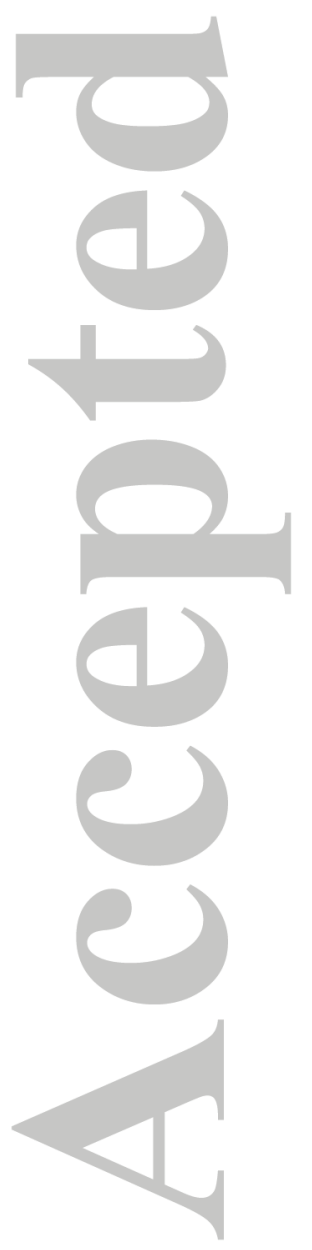




\section{Table 1}

\section{(Li et al.)}

\begin{tabular}{|c|c|}
\hline Parameters & Values \\
\hline Average operating flux, $\mathrm{J}_{\mathrm{e}}$ & $10-25 \mathrm{~L} /\left(\mathrm{m}^{2} . \mathrm{h}\right)$ \\
\hline Inside diameter, $\mathrm{d}$ & $0.5-1.0 \mathrm{~mm}$ \\
\hline Ratio of inside and outside diameter, $\mathrm{d} / \mathrm{D}$ & $1: 2$ \\
\hline Allowable pressure drop, $\Delta \mathrm{P}_{\mathrm{tp}}$ & $5 \mathrm{kPa}$ \\
\hline Standard atmospheric pressure and, $\mathrm{P}_{\mathrm{o}}$ & $101.3 \mathrm{kPa}$ \\
\hline Membrane intrinsic resistance, $\mathrm{R}_{\mathrm{t}}$ & $6 \times 10^{11} \mathrm{~m}^{-1}$ \\
\hline Feed liquid viscosity, $\mu_{o}$ & $1.5 \times 10^{-3} \mathrm{~Pa} . \mathrm{s}$ \\
\hline Feed liquid density, $\rho_{o}$ & $1100 \mathrm{~kg} / \mathrm{m}^{3}$ \\
\hline Water viscosity, $\mu$ & $1 \times 10^{-3} \mathrm{~Pa} . \mathrm{s}$ \\
\hline Water density, $\rho$ & $1000 \mathrm{~kg} / \mathrm{m}^{3}$ \\
\hline $\begin{array}{l}\text { Aeration rate per unit cross section area of } \\
\text { module, } \mathrm{Q}_{\mathrm{o}}\end{array}$ & $5 \mathrm{~m}^{3} /\left(\mathrm{m}^{2} . \mathrm{h}\right)$ \\
\hline
\end{tabular}

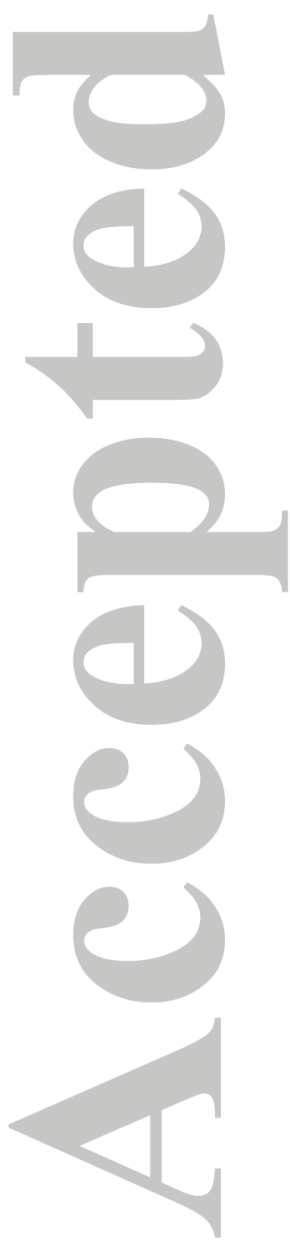




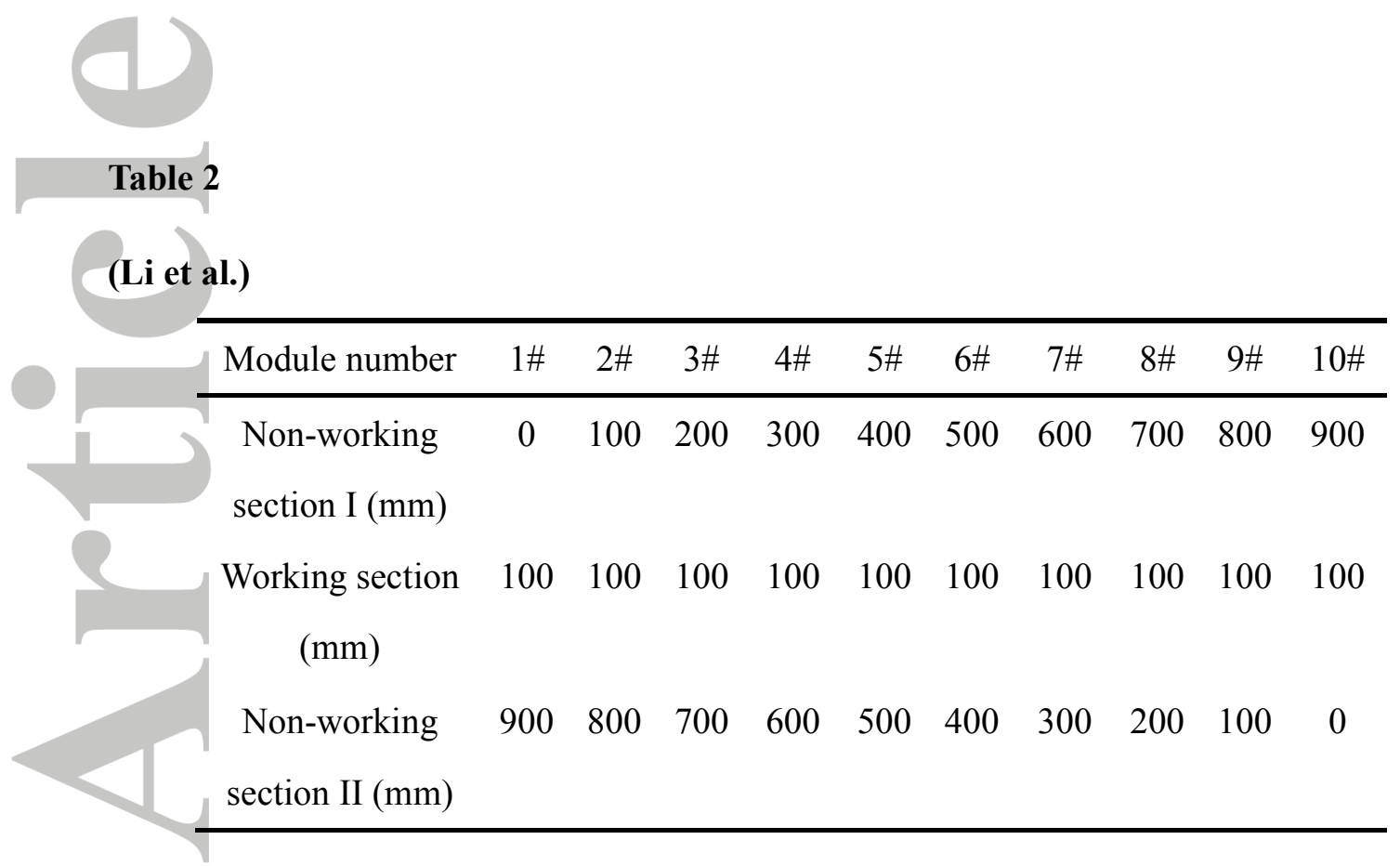

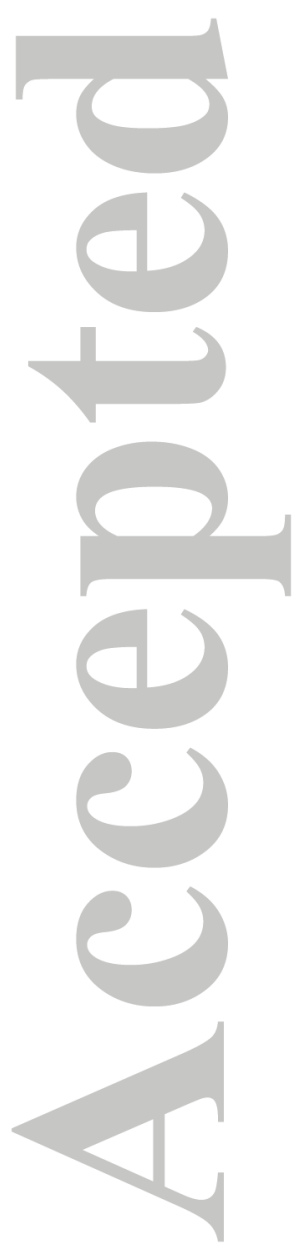


Table 3

\section{(Li et al.)}

\begin{tabular}{|c|c|c|c|c|c|c|c|c|c|c|}
\hline $\mathrm{Z}(\mathrm{mm})$ & 50 & 150 & 250 & 350 & 450 & 550 & 650 & 750 & 850 & 950 \\
\hline $\begin{array}{l}\text { Local flux at } \\
\text { average operating } \\
\text { flux of } 10 \mathrm{~L} /\left(\mathrm{m}^{2} . \mathrm{h}\right)\end{array}$ & $6.7 \pm 0.5$ & $6.9 \pm 0.5$ & $7.2 \pm 0.8$ & $7.6 \pm 1.0$ & $8.5 \pm 1.0$ & $9.2 \pm 1.0$ & $10.6 \pm 1.2$ & $11.7 \pm 1.2$ & $13.6 \pm 1.5$ & $15.6 \pm 1.5$ \\
\hline $\begin{array}{l}\text { Local flux at } \\
\text { average operating } \\
\text { flux of } 15 \mathrm{~L} /\left(\mathrm{m}^{2} . \mathrm{h}\right)\end{array}$ & $10.2 \pm 0.5$ & $10.4 \pm 0.5$ & $10.8 \pm 1.0$ & $11.7 \pm 1.0$ & $12.5 \pm 1.0$ & $13.8 \pm 1.5$ & $15.7 \pm 1.5$ & $18.3 \pm 1.5$ & $20.2 \pm 2.0$ & $22.4 \pm 2.0$ \\
\hline
\end{tabular}




\begin{tabular}{|c|c|c|}
\hline (Li et al.) & & \\
\hline & Parameters & Values \\
\hline & Fiber length, L & $2.0 \mathrm{~m}$ \\
\hline & Fiber inside diameter, $\mathrm{d}$ & $0.9 \mathrm{~mm}$ \\
\hline & Fiber outside diameter, $\mathrm{D}$ & $1.9 \mathrm{~mm}$ \\
\hline & Membrane intrinsic resistance, $R_{t}$ & $6 \times 10^{11} \mathrm{~m}^{-1}$ \\
\hline & Water viscosity, $\mu$ & $1 \times 10^{-3} \mathrm{~Pa} . \mathrm{s}$ \\
\hline & Water density, $\rho$ & $1000 \mathrm{~kg} / \mathrm{m}^{3}$ \\
\hline
\end{tabular}

